\title{
PROGRAMAS CONDICIONAIS DE TRANSFERÊNCIA DE RENDA E FECUNDIDADE: EVIDÊNCIAS DO BOLSA FAMÍLIA
}

\author{
Romero Cavalcanti Barreto da Rocha *
}

\begin{abstract}
Resumo
Este trabalho tem como objetivo aprofundar a investigação em relação aos efeitos dos programas condicionais de transferência de renda, nos quais a quantidade de recursos transferidos depende do tamanho da família, sobre a fecundidade das mães beneficiárias. O efeito desse tipo de programa é ambíguo. O custo de ter filhos é diminuído, mas aumenta-se o investimento em capital humano. O objetivo deste artigo é verificar se o Programa Bolsa Família teve impacto na probabilidade de a mulher ter filhos e qual o sinal dessa correlação. Para isso, foram testadas três diferentes estratégias empíricas e não foi encontrado efeito robusto do programa na fecundidade em nenhuma delas.
\end{abstract}

Palavras-chave: programas condicionais; transferência de renda; fecundidade.

\begin{abstract}
The aim of this work is to contribute with the investigation about the demographic externalities of the Conditional Cash Transfer Programs (CCT). The effect of CCTs on fertility is ambiguous. It decreases the cost of raising children but increases human capital investment. The objective of this work is to verify if the "Bolsa Família" has an effect on the probability of a woman having a child and what is the signal of this correlation. To this end, we tried three different empirical strategies and, in none of them, we found any robust effect of the program on fertility.
\end{abstract}

Keywords: conditional cash transfers; fertility; public policies.

JEL classification: J13, J18, I38.

DOI: http://dx.doi.org/10.11606/1980-5330/ea168739

\footnotetext{
* Instituto de Economia da Universidade Federal do Rio de Janeiro. E-mail: romero.rocha@ie.ufrj.br.
} 


\section{Introdução}

Este trabalho tem como objetivo investigar o efeito sobre incentivo a fecundidade dos programas condicionais de transferência de renda (PCTR), nos quais a quantidade de recursos transferidos depende do tamanho da família. A maior preocupação é que esses programas estejam incentivando famílias que já são pobres a terem mais filhos, o que poderia gerar uma espécie de armadilha da pobreza. Por outro lado, muitos desses programas exigem contrapartida dos beneficiários, como investimento em educação dos filhos, o que poderia gerar incentivo contrário, ou seja, incentivo a ter menos filhos. Esse maior investimento em capital humano ajudaria essas famílias a escaparem da armadilha da pobreza acima citada. Portanto, o efeito desse tipo de programa é ambíguo. O objetivo deste artigo é verificar se o Programa Bolsa Família $(\mathrm{PBF})$ teve impacto na probabilidade da mulher beneficiária ter filhos e qual o sinal dessa correlação.

O PBF é um programa de transferência de renda condicional, no qual as famílias recebem uma transferência do governo caso ganhem até certo limite de renda domiciliar per capita e tenham filhos ou mulheres grávidas no domicílio. Em contrapartida os beneficiários têm que investir no capital humano dos filhos, cumprindo condições tanto na área de saúde, quanto na de educação. Assim, percebe-se que o programa tem características que o tornam um PCTR, mencionado no parágrafo anterior. O programa é centro de debate na política brasileira, recebendo tanto elogios entusiastas, quanto críticas fervorosas, principalmente críticas que o acusam de ser puramente assistencialista, de diminuir a oferta de trabalho e de incentivar a fecundidade. Por exemplo, o Deputado Marden Menezes, em discurso na tribuna da câmera afirmou: "Há relatos de mães que tem filhos todos os anos para ter direito a mais dinheiro do Bolsa Família, daí a explosão de bolsões de pobreza" (Deputado Marden Menezes, 2009). Já o economista Marcelo Medeiros do IPEA afirma que: "Dizer que a possibilidade de receber uma bolsa é suficiente para estimular milhares de famílias a ter filhos é ou ingenuidade ou uma proposta dissimulada para reduzir custos dos programas excluindo os mais pobres." (Medeiros 2004). Portanto, a discussão ainda não tem um consenso e o debate precisa de evidências econométricas, ainda inexistentes ou com conclusões ambíguas. A mesma preocupação pode ser vista em programas parecidos em outros países, como o PROGRESA no México, o PRAF em Honduras, o RPS na Nicarágua, o PATH na Jamaica e o FFE em Bangladesh (Janvry \& Sadoulet 2006, Skoufias 2001, Todd \& Wolpin 2006, Handa \& Davis 2006, Barrientos \& Dejong 2006).

Desde Malthus, os pesquisadores têm tentado estabelecer uma correlação entre transferência de renda às famílias necessitadas e número de filhos que essas famílias têm. Para Malthus, a Old Poor Law da Inglaterra do século XIX incentivava as pessoas a terem mais filhos, principalmente ao incentivarem os casais a se casarem mais cedo. Pesquisadores atuais sobre o assunto chegam a resultados ambíguos a respeito das afirmações de Malthus. Alguns trabalhos encontram resultados que lhe dão razão enquanto outros não encontram nenhum efeito da lei sobre o número de filhos das mulheres da época (Boyer 1989, Huzel 1980).

Políticas mais recentes também têm despertado interesse dos pesquisadores atuais. Com boa parte do mundo já tendo passado pela transição demográfica é provável que os efeitos desse tipo de programa sejam realmente bem diferentes hoje. Vários trabalhos tentam estabelecer a correlação entre trans- 
ferência de renda que dependem do tamanho da família aos mais pobres e fecundidade. Em países desenvolvidos, essas transferências podem ser na forma de transferência direta ou de isenção de impostos. Os resultados encontrados nos trabalhos sobre esses países são ambíguos (Acs 1996, Gathier \& Hatzius 1997, Whittington et al. 1990).

Entretanto, o interesse maior deste trabalho é sobre os efeitos desse tipo de transferência sobre as externalidades demográficas nos países em desenvolvimento, onde os problemas demográficos podem agravar as situações de pobreza. Além disso, nos países em desenvolvimento, esses programas têm em comum a exigência de contrapartidas tanto na área de saúde, como na área de educação, o que pode criar outro mecanismo através do qual o efeito pode ser encontrado que é o mecanismo do investimento em capital humano dos filhos. Ao financiar o investimento em capital humano dos filhos dos beneficiários, esses programas podem estar dando incentivos para os pais trocarem quantidade de filhos por qualidade de filhos já que essas duas coisas são substitutas, levando a uma diminuição da taxa de fecundidade (Schultz 1997).

O trabalho que mediu o efeito desse tipo de programa em países da América Latina também chegou a resultados ambíguos. Stecklov et al. (2006), mediram o efeito do Programa de Educação, Saúde e Nutrição (PROGRESA), no México, do Programa de Assistência Familiar (PRAF), em Honduras e da Rede de Proteção Social (RPS), na Nicarágua, sobre a fecundidade desses três países e encontraram efeito apenas no caso do PRAF, em Honduras. Nos outros dois países, nenhum efeito significativo foi encontrado. Além disso, Todd \& Wolpin (2006), usaram um modelo dinâmico de comportamento, validado por dados experimentais do PROGRESA, para tentar predizer, ex-ante, o efeito dos subsídios escolares desse programa na fecundidade e chegaram à conclusão que os subsídios não teriam efeito significativo na média, nem na distribuição do número de filhos dos beneficiários.

A intenção deste trabalho é contribuir para o debate do efeito de Programas Condicionais de Transferência de Renda (PCTR's), verificando o efeito do programa brasileiro Bolsa Família sobre a fecundidade dos beneficiários. O Programa Bolsa Família também é um programa parecido com os programas dos três países citados acima, no qual existem contrapartidas em educação e saúde exigidas e a quantidade de recursos recebidos depende do tamanho da família. O programa tem desvantagens em relação a esses outros no que diz respeito à facilidade de calcular o impacto na fecundidade porque ele não teve uma fase experimental. Em contrapartida, as várias dimensões de regras de entrada existentes no PBF nos ajuda a criar métodos quase-experimentais para calcular esse impacto.

Nós tentamos três diferentes metodologias para calcular o impacto do programa em fecundidade. Na primeira, criamos grupos de tratamento e controle nas dimensões de renda per capita e número de filhos para fazer um dif-emdif-em-dif, com as PNADs de 1995 a 2007, levando em conta que o programa teve início no final de 2003. Na segunda, usamos o suplemento da PNAD 2006 com a informação se o domicílio recebe o programa e cruzamos essa informação com o grupo de tratamento na dimensão de número de filhos para ver se, dado que o domicílio recebe o programa, o fato dele poder receber ainda um benefício a mais aumenta a probabilidade de nascimento. Na terceira, mantemos apenas as famílias com um e dois filhos e usamos também o suplemento da PNAD 2006 para fazer um "propensity score matching" e calcular o efeito de tratamento nos tratados a partir do método do vizinho mais próximo, com 
suporte comum. Nas três tentativas, os resultados encontrados mostram que o programa não tem efeito significativo na fecundidade dos beneficiários.

O restante do trabalho se divide da seguinte forma: a Seção 2 discute a teoria e os principais mecanismos pelos quais o programa teria efeito; a Seção 3 faz uma descrição e detalhamento do Programa Bolsa Família; a Seção 4 discute os dados e as estratégias empíricas do trabalho; a Seção 5 discute os resultados do trabalho; e a Seção 6 traz as conclusões do trabalho e suas implicações para políticas públicas.

\section{Teoria e Debate}

Os custos diretos e indiretos de criar uma criança são, em geral, substanciais. A criança necessita de gastos referentes à nutrição, saúde, roupa, escola e outros. Além disso, um filho também exige atenção, tempo e cuidados especiais que podem trazer custos de oportunidade ao fazer com que as mulheres trabalhem menos ou até abandonem o trabalho. Um programa de transferência de renda, no qual o valor transferido depende do número de filhos, pode diminuir esses custos e incentivar fecundidade.

Este é um dos motivos pelos quais todos os PCTRs da América Latina têm limite na quantidade de filhos com direito a recursos. Essa dimensão nos desenhos dos programas é importante por causa da diferença dos custos do primeiro filho para os custos dos demais filhos. Estimações feitas nos EUA mostram que o custo marginal do primeiro filho é substancialmente maior que o dos demais filhos, assim como o custo marginal do segundo filho é maior que o do terceiro e assim por diante (Williams 1987). Isso pode ser importante na medida em que, se o recurso é constante por criança concebida, a relação custo benefício é menor no terceiro benefício que no segundo e também é menor neste que no primeiro. Portanto, na medida em que cresce o limite dos benefícios, mais incentivo à fecundidade esses recursos poderiam estar gerando.

Por outro lado, mesmo um programa de transferência de renda lump sum, que não tenha condicionalidades, pode afetar negativamente a fecundidade por diminuir os custos de se investir na qualidade dos filhos. Stecklov et al. (2006), analisaram esse problema utilizando como base o modelo padrão de fecundidade de Becker (1960) e Becker \& Lewis (1973). Segundo eles, o efeito de um programa incondicional de transferência de renda, ou seja, de uma transferência lump sum, depende das elasticidades de renda de quantidade de filhos e de qualidade de filhos, que por sua vez, dependem das preferências dos pais em relação a esse trade-off. Portanto, o efeito de um programa desse tipo sobre fecundidade é ambíguo.

$\mathrm{O}$ incentivo a investir na qualidade dos filhos pode ser ainda maior nos programas de transferência de renda que tenham como condições o investimento em educação e saúde dos filhos e na saúde de mulheres grávidas, o que acontece na maioria dos programas de transferência de renda que estão sendo implantados na América Latina. Essas condicionalidades em relação à saúde e educação diminuem os custos de se investir na qualidade dos filhos. Isso pode gerar uma mudança no trade-off quantidade-qualidade na direção do investimento em qualidade, o que geraria incentivo à redução na fecundidade (Schultz 1997). 
Quais dessas forças (diminuição dos custos de quantidade e diminuição nos custos da qualidade dos filhos) predominam no efeito dos programas condicionais de transferência de renda sobre fecundidade depende da, percentagem da redução dos custos do investimento em quantidade e qualidade. Se o percentual da redução dos custos de investimento em quantidade for maior, é provável que o incentivo seja de aumento na fecundidade. Se, por outro lado, os custos de investimento em qualidade forem os mais afetados, o incentivo será para a redução da fecundidade. Se a ênfase das condições do programa tiver o mesmo peso na redução dos custos relacionados à qualidade e à quantidade é provável que o incentivo maior seja para um aumento da fecundidade (Stecklov et al. 2006).

Por último, é importante discutir o impacto dos PCTR's sobre a oferta de crianças, ou seja, sobre a condição de fertilidade das mulheres. Como a maioria desses programas tem dimensões de planejamento familiar, de informação em relação à saúde e nutrição (incluindo nutrição para mães que estão amamentando) e a métodos de controle de nascimento, é possível que eles afetem tanto a capacidade da mulher ter filhos, quanto o controle realizado de nascimentos. A restrição orçamentária do domicílio é, portanto, aumentada para incluir os recursos usados para o controle de fertilidade, um parâmetro de efetividade e os custos totais desse controle (Rosenzweig \& Schultz 1985). PCTR's podem diminuir os custos do controle ao nascimento, tanto diminuindo o custo de transação associado à obtenção do controle (ou seja, uma redução nos preços do controle), quanto aumentando a efetividade desse controle. Portanto, os programas podem ter efeito de diminuição da fecundidade. Ao mesmo tempo, ao incentivar a amamentação dos filhos o programa pode estar expandindo a duração da infecundidade pós-parto, o que pode gerar nascimentos mais espaçados, diminuindo assim, as taxas de fertilidade (Bongaarts 1982).

Percebe-se que os efeitos teóricos dos PCTR's na fecundidade e na fertilidade são bastante ambíguos e o sinal dessa relação torna-se, portanto, um exercício essencialmente empírico. Como veremos na próxima seção, todas as dimensões acima discutidas estão presentes no desenho do Programa Bolsa Família, tornando assim, o desafio de estabelecer o efeito do programa sobre fecundidade, ainda mais estimulante.

\section{Descrição e Histórico do Programa}

O Programa Bolsa Família é um programa condicional de transferência de renda com foco nos mais pobres que exige como contrapartida para as famílias investimentos em saúde infantil, saúde de grávidas e frequencia escolar. Foi um programa criado em outubro de 2003, originado da junção de vários programas já existentes do governo federal, como o Bolsa Escola, o Bolsa Alimentação e o Programa de Erradicação do Trabalho Infantil (PETI).

O Programa de Erradicação do Trabalho Infantil foi criado em 1996 e consiste em uma transferência de renda para famílias com crianças de 7 a 15 anos que trabalham ou que corram o risco de ter que trabalhar em atividades que sejam prejudiciais à sua saúde. A transferência era de $\mathrm{R} \$ 25,00$ por criança nas áreas rurais e de $\mathrm{R} \$ 40,00$ nas áreas urbanas. A contrapartida para as famílias era que as crianças com menos de 16 anos não trabalhassem e que elas tivessem, no mínimo, 75\% de frequencia escolar. 
Em 2001 o governo federal criou os outros dois programas. O Bolsa Escola era focalizado em famílias com filhos entre 6 e 15 anos de idade que ganhassem menos que $R \$ 90$ reais per capita. As famílias ganhariam $R \$ 15,00$ por mês, por criança nessa idade, até o terceiro filho e teriam que se comprometer a assegurar no mínimo uma frequencia de $85 \%$ das crianças na escola. O PETI e o Bolsa Escola não deveriam ter, em teoria efeito sobre fecundidade, já que os benefícios começavam a ser distribuídos, somente, quando a criança completava 7 ou 6 anos respectivamente. Entretanto, o Programa Bolsa Alimentação, também criado em 2001, era um programa que tinha como objetivo combater a mortalidade infantil em famílias com crianças de 0 a 6 anos ou mulheres grávidas e com renda mensal per capita de até metade de um salário mínimo. $\mathrm{O}$ valor do benefício era de $\mathrm{R} \$ 15,00$ por criança ou mulher grávida, até o máximo de $\mathrm{R} \$ 45,00$. Em contrapartida, as famílias se comprometeriam em atualizar o cartão de vacinação das crianças de 0 a 6 anos, como também a fazer com que as mulheres grávidas fizessem visitas regulares aos postos de saúde para o prénatal. Embora esse programa já pudesse ter algum efeito sobre fecundidade, a cobertura dele era muito pequena, o que nos leva a crer que apenas com o PBF esse efeito poderia ser realmente captado.

O PBF foi um programa criado em Outubro de 2003 que unificou os programas discutidos acima. A Tabela 1 descreve as regras de entrada no programa e os valores dos benefícios pagos. Na época da criação, ele era focalizado em famílias com renda per capita mensal máxima de $\mathrm{R} \$ 100,00$ e com crianças de 0 a 15 anos, ou famílias com renda per capita máxima de $\mathrm{R} \$ 50$, independente do número de crianças. Em 2006, esses valores aumentaram para $R \$ 120,00$ e $R \$ 60,00$, respectivamente. Os benefícios pagos em 2003 eram de $\mathrm{R} \$ 15,00$ por filho, até o terceiro filho para as famílias que recebessem até $\mathrm{R} \$ 100,00$ per capita e mais um fixo de $\mathrm{R} \$ 50$ reais para as famílias que recebessem até $\mathrm{R} \$ 50,00$ per capita mensais. Em 2006, os benefícios passaram a ser de $R \$ 20,00$ e $R \$ 60,00$, respectivamente. O ponto de corte mais baixo do programa (abaixo de 50 reais per capita até 2006 e de 60 reais per capita a partir desse ano) não interessa muito no nosso caso, porque ele é independente do número de filhos.

Tabela 1: Regras de entrada e benefícios do Bolsa Família

\begin{tabular}{l|ccc}
\hline & $\begin{array}{c}\text { Ponto de Corte (Renda } \\
\text { Domiciliar per capita) (R\$) }\end{array}$ & $\begin{array}{c}\text { Benefício } \\
\text { Fixo (R\$) }\end{array}$ & $\begin{array}{c}\text { Benefício } \\
\text { Variável (R\$) }\end{array}$ \\
\hline Até 2005 & 50,00 & 50,00 & 15,00 por filho até 3 filhos \\
& Entre 50,00 e 100,00 & 0,00 & de no máximo 15 anos \\
\hline A partir de 2006 & 60,00 & 60,00 & 20,00 por filho até 3 filhos \\
& Entre 60,00 e 120,00 & 0,00 & de no máximo 15 anos \\
\hline
\end{tabular}

Em contrapartida ao benefício, as famílias devem manter atualizados os cartões de vacinação das crianças de 0 a 6 anos, as crianças de 6 a 15 anos devem estar matriculadas na escola e com uma frequencia mínima de $85 \%$ e visitas regulares ao posto de saúde são exigidas tanto para grávidas, para o pré- natal, como para as mães que estão amamentando.

O impacto do Programa Bolsa Família sobre a desigualdade no Brasil parece ter sido substancial. O índice de Gini no Brasil caiu de 59,9 em 1995 para 57,1 em 2004. Vários pesquisadores estudaram o efeito do programa na redução de desigualdade brasileira no começo deste século e todos chegam à 
conclusão de que o programa teve uma parcela importante de responsabilidade nessa redução. (Soares et al. 2007, Hoffmann 2007, Barros 2007). Além disso, também é possível mostrar que programas de transferência de renda, com foco nos mais pobres, como o Bolsa Família, foram mais efetivos para a diminuição de pobreza e desigualdade no Brasil do que políticas pautadas no Salário Mínimo (Barros 2007). Isso significa que as transferências eram realmente substanciais para as famílias e, por isso, existem tantas preocupações com os efeitos indiretos que elas podem acarretar.

Uma série de estudos foi feita sobre os impactos do Programa Bolsa Família e de seu semelhante anterior (o Bolsa Escola) em variáveis comportamentais, como oferta de trabalho adulta, oferta de trabalho das mães, frequencia escolar e trabalho infantil. Cardoso \& Souza (2004) mostraram que o programa Bolsa Escola tinha impacto positivo e significativo sobre a frequencia escolar dos beneficiários e não tinha impacto sobre o trabalho infantil. Segundo eles, o programa fez com que aumentasse o número de crianças que só estudam e também o número de crianças que trabalham e estudam, mas diminuiu o número de crianças que apenas trabalham e não estudam. Duarte \& Silveira Neto (2008) também mostram que a frequencia escolar dos beneficiários do Programa Bolsa Família na agricultura familiar do Nordeste é maior que a dos não beneficiários. Resende \& Oliveira (2006) mostram que o programa eleva os gastos das famílias com consumo de alimentos, produtos de higiene, educação e vestuário, o que representaria um aumento de bem-estar dessas famílias. Ao mesmo tempo, Chein et al. (2006) tentam estabelecer uma causalidade do recebimento do programa com a condição nutricional das crianças e não encontram efeito robusto entre os domicílios beneficiados. Por último, Tavares (2008) mostra que o impacto do programa sobre a oferta de trabalho das mães é positivo e Foguel \& Barros (2008) mostram que o programa não tem impacto significativo sobre a oferta de trabalho adulta.

Foram encontrados dois trabalhos sobre o efeito do PBF na fecundidade. Signorini \& Queiroz (2009) não encontram efeito significativo do programa na fecundidade e Simões \& Soares (2012) encontra efeito negativo do programa sobre fecundidade. Entretanto, nossa metodologia difere bastante desses trabalhos e nós acreditamos que estamos, assim, dando nossa contribuição para o debate.

\section{Dados e Estratégias Empíricas}

Os dados utilizados neste trabalho são dados anuais da PNAD de 1995 a 2007 (com exceção de 2000), com informações sócio-econômicas e demográficas de domicílios que tenham mulheres de 15 a 50 anos. Além disso, usaremos o suplemento adicional da PNAD 2006 com informações sobre se o domićlilio tinha alguém que recebia o Programa Bolsa Família.

A Tabela 2 mostra estatísticas descritivas das mulheres de 15 a 50 anos, com renda domiciliar per capita menor que quatro vezes o ponto de corte para ser elegível para o PBF e com zero, um, dois ou três filhos entre 1 e 14 anos de 1995 a 2007. A ideia é que as mulheres com zero, um e dois filhos na idade referida são as mulheres que ainda podem se beneficiar tendo mais um filho com o programa Bolsa Família, enquanto as mulheres que já têm três filhos nessa idade não se beneficiariam com um quarto filho. Isso vai ser importante para construir nossos grupos de tratamento e controle, como veremos posteri- 
ormente.

Verifica-se que os padrões de fecundidade, educação e renda são bastante parecidos entre as mulheres que têm zero ou um filho e também entre as mulheres que têm dois ou três filhos. Entretanto, ele parece ser bem diferente entre esses dois grupos. As mulheres com dois filhos tinham uma probabilidade de ter um filho de 7,3\% em 1995 e de 4,9\% em 2007, enquanto as com três filhos tinham uma probabilidade de 7,3\% em 1995 e de 5,1\% em 2007. Ao mesmo tempo, para as mulheres com nenhum filho, essas probabilidades eram de $8,9 \%$ e $6,0 \%$ e para as com um filho eram de $9,1 \%$ e $6,1 \%$. Padrões parecidos se verifica nas demais variáveis, embora em algumas delas as características das mulheres com três filhos sejam mais diferentes em relação às mulheres com dois filhos do que são em termos de padrão de fecundidade.

A Tabela 3 mostra estatísticas descritivas para a PNAD 2006 com informação de se o domicílio recebe Bolsa Família ou não. Pode-se ver que a maioria das pessoas que recebem o programa é do Nordeste. Além disso, o Nordeste também é a região na qual a percentagem da população que recebe o programa é a maior. Por último, é importante frisar que, segundo essa tabela, muita gente que está acima do ponto de corte de renda, mas abaixo de duas vezes o ponto de corte também recebe o programa. Por isso, vamos tomar certos cuidados ao definir controle e tratamento.

Para caracterizarmos o efeito do Programa Bolsa Família na fecundidade das beneficiárias, vamos usar três diferentes estratégias. Na estratégia 1, vamos nos aproveitar das regras de entrada explicadas na seção anterior para construir um modelo de diferenças em diferenças em diferenças. Assim, vamos manter na amostra apenas as mulheres que estão em domicílios com renda domiciliar per capita menor que duas vezes o ponto de corte e que tenha dois ou três filhos com idade entre 1 e 14 anos. A escolha dessa idade é explicada pelo fato que aos 16 anos o filho deixa de receber o programa, portanto, a mãe poderia ter um filho a mais para repor a perda de renda com o fato de que um de seus filhos completou 16 anos. Além disso, a variável dependente escolhida será se a mulher teve um filho nascido vivo nos últimos 12 meses e, portanto, vamos excluir da conta de número de filhos, o filho nascido nesse período. Já a escolha pelas mulheres com dois ou três filhos foi feita por causa do padrão de características parecidas no período analisado. Assim, na dimensão número de filhos, teremos como grupo de tratamento as mulheres que têm dois filhos e que ainda podem ser beneficiadas pelo programa com um terceiro filho. E como grupo de controle as mulheres com três filhos, que não podem ser beneficiadas pelo programa tendo um filho a mais. A outra diferença que iremos tirar será em relação às mulheres que estão na faixa de renda domiciliar per capita que as torna elegível para receber o programa. Estas serão o grupo de tratamento. O grupo de controle será composto pelas mulheres que estão acima desse ponto de corte, mas abaixo de duas vezes o ponto de corte. Novamente, a intenção é manter os grupos com características mais próximas o possível. Por último, vamos também criar uma dummy que assumirá valor um, caso o ano seja depois do ano de implementação do programa, 2003, e zero caso contrário. A especificação, portanto, será a seguinte:

$$
\text { nasceu }_{i}=\alpha+\gamma F_{i}+\lambda B F_{i}+\mu\left(F_{i}^{*} B F_{i}\right)+\sum X_{i}+\epsilon
$$

Em que nasceu $u_{i}$ é uma dummy que assume valor um se a mulher $i$ teve um filho nascido vivo nos últimos doze meses; $F_{i}$ é uma dummy que assume valor 
Tabela 2: Estatísticas descritivas, PNADs 1995 a 2007

\begin{tabular}{|c|c|c|c|c|c|c|c|c|}
\hline \multirow[b]{2}{*}{ Ano } & \multicolumn{4}{|c|}{ Nenhum Filho } & \multicolumn{4}{|c|}{1 Filho } \\
\hline & Teve Filho & Educação & Urbano & Renda Dom per capita & Teve Filho & Educação & Urbano & Renda Dom per capita \\
\hline 1995 & 0,089 & 6,776 & 0,838 & 112,803 & 0,091 & 6,609 & 0,831 & 103,845 \\
\hline 1996 & 0,080 & 6,940 & 0,842 & 125,657 & 0,083 & 6,755 & 0,828 & 115,213 \\
\hline 1997 & 0,078 & 7,026 & 0,839 & 132,647 & 0,086 & 6,832 & 0,832 & 122,131 \\
\hline 1998 & 0,077 & 7,211 & 0,839 & 137,487 & 0,082 & 7,090 & 0,831 & 125,712 \\
\hline 1999 & 0,076 & 7,508 & 0,849 & 144,897 & 0,077 & 7,350 & 0,830 & 130,663 \\
\hline 2001 & 0,069 & 7,894 & 0,877 & 170,207 & 0,072 & 7,624 & 0,864 & 145,775 \\
\hline 2002 & 0,064 & 7,992 & 0,870 & 181,069 & 0,072 & 7,724 & 0,862 & 153,594 \\
\hline 2003 & 0,066 & 8,088 & 0,865 & 187,724 & 0,070 & 7,864 & 0,855 & 160,223 \\
\hline 2004 & 0,064 & 8,213 & 0,851 & 210,044 & 0,067 & 8,045 & 0,835 & 179,927 \\
\hline 2005 & 0,066 & 8,236 & 0,844 & 218,622 & 0,069 & 8,107 & 0,828 & 189,853 \\
\hline 2006 & 0,065 & 8,475 & 0,848 & 256,845 & 0,065 & 8,389 & 0,839 & 218,317 \\
\hline \multirow[t]{2}{*}{2007} & 0,060 & 8,530 & 0,845 & 261,403 & 0,061 & 8,493 & 0,836 & 227,236 \\
\hline & \multicolumn{4}{|c|}{2 Filhos } & \multicolumn{4}{|c|}{3 Filhos } \\
\hline Ano & Teve Filho & Educação & Urbano & Renda Dom per capita & Teve Filho & Educação & Urbano & Renda Dom per capita \\
\hline 1995 & 0,073 & 6,404 & 0,814 & 92,775 & 0,073 & 6,028 & 0,791 & 84,106 \\
\hline 1996 & 0,070 & 6,587 & 0,816 & 103,149 & 0,067 & 6,183 & 0,791 & 92,198 \\
\hline 1997 & 0,069 & 6,622 & 0,811 & 107,842 & 0,067 & 6,190 & 0,790 & 95,634 \\
\hline 1998 & 0,065 & 6,809 & 0,810 & 110,396 & 0,068 & 6,365 & 0,787 & 99,665 \\
\hline 1999 & 0,063 & 7,061 & 0,807 & 115,759 & 0,067 & 6,594 & 0,784 & 102,991 \\
\hline 2001 & 0,059 & 7,084 & 0,840 & 117,139 & 0,064 & 6,121 & 0,802 & 86,458 \\
\hline 2002 & 0,054 & 7,268 & 0,839 & 126,215 & 0,059 & 6,278 & 0,792 & 92,992 \\
\hline 2003 & 0,054 & 7,402 & 0,839 & 130,400 & 0,056 & 6,353 & 0,787 & 94,625 \\
\hline 2004 & 0,055 & 7,459 & 0,815 & 147,015 & 0,059 & 6,519 & 0,751 & 107,316 \\
\hline 2005 & 0,055 & 7,581 & 0,801 & 153,843 & 0,058 & 6,581 & 0,750 & 117,475 \\
\hline 2006 & 0,050 & 7,800 & 0,803 & 176,269 & 0,052 & 6,844 & 0,748 & 132,438 \\
\hline 2007 & 0,049 & 7,928 & 0,810 & 184,220 & 0,051 & 6,858 & 0,754 & 137,019 \\
\hline
\end{tabular}


Tabela 3: Estatísticas descritivas PNAD 2006

\begin{tabular}{l|rr|r}
\hline & \multicolumn{2}{|c|}{ Recebe BF } & \\
& Não & \multicolumn{1}{c|}{ Sim } & Total \\
\hline Norte & 4,841 & 2,556 & 7,397 \\
Nordeste & 10,629 & 10,589 & 21,218 \\
Sudeste & 6,903 & 3,108 & 10,011 \\
Sul & 3,106 & 1,260 & 4,366 \\
Centro-Oeste & 3,410 & 1,059 & 4,469 \\
\hline Acima do Treshold & 18,796 & 7,193 & 25,989 \\
Abaixo do Treshold & 10,093 & 11,379 & 21,472 \\
\hline Total & 28,889 & 18,572 & 47,461 \\
\hline
\end{tabular}

um se a mulher $i$ tem dois filhos entre 1 e 14 anos e valor zero caso tenha três filhos nessa mesma faixa etária; $B F_{i}$ é uma dummy que assume valor um se a mulher está em um domicílio que recebe o Programa Bolsa Família e zero caso contrário; $X_{i}$ é um vetor de variáveis de controle com as mesmas variáveis que no caso anterior; e o coeficiente de interesse $\mu$ é o coeficiente da interação entre as dummies de filho e de recebimento do programa.

Da mesma forma que no caso anterior, como muitas acima do ponto de corte recebem, vamos ampliar a amostra para incluir todas as mulheres que recebem até duas vezes o ponto de corte de renda e também para incluir no tratamento aquelas com apenas um filho. Não incluiremos nesse caso as mulheres com nenhum filho porque estas dificilmente recebem o programa e, mesmo quando recebem, o recebimento não é devido ao número de filhos. Como a intenção é verificar se, dado que elas recebem, existe o incentivo delas ainda poderem ter mais um filho e receber mais um benefício, não faz sentido colocar um grupo que praticamente não tem nenhuma mulher recebendo (o grupo das mulheres com nenhum filho). Mais uma vez, vamos verificar os efeitos por faixa etária da mulher.

Faremos também as estimações das especificações básicas dessas duas primeiras estratégias com probit. Para o cálculo dos efeitos marginais dos coeficientes de interação usaremos o método do efeito de interação, que é diferente do efeito marginal do termo de interação (Ai \& Northon 2003). Usaremos, portanto, o comando do Stata "inteff" para os casos onde temos apenas interação dupla e o comando "inteff3", para os casos onde temos interação tripla (Norton et al. 2004, Cornelissen \& Sonderhof 2008).

Na estratégia 3, também usaremos a PNAD 2006 com o suplemento que identifica se a mulher recebe o Programa Bolsa Família para estimar um propensity score dessa mulher receber o programa nas variáveis observáveis, as mesmas usadas como controle nas demais estratégias e posteriormente usar esse escore de propensão para estimar um modelo matching pelo método do vizinho mais próximo, usando apenas suporte comum. O grupo de tratamento serão aquelas mulheres com um ou dois filhos que estão na faixa de renda que as torna elegível e que recebem o programa. Já o grupo do controle serão as mulheres que têm um ou dois filhos que estão na faixa de renda elegível, mas que não recebem o programa. Teoricamente, esse grupo já deveria estar recebendo o programa, então a diferença entre os grupos é que um recebe e o outro não. Além disso, se existe outras características observáveis que são importantes para determinar o recebimento ou não do programa, o método do vizinho 
mais próximo irá comparar tratamento e controle apenas com os pares que têm características que os deixam com probabilidade de recebimento do programa mais próxima. Com isso, conseguiremos estimar o efeito de tratamento médio nos tratados. A variável dependente continua sendo se a mulher teve um filho nos últimos doze meses. O primeiro estágio do modelo é um probit que examina a probabilidade da mulher receber o programa, dadas suas características. O modelo é:

$$
P\left(X_{i}\right) \equiv \operatorname{Pr}\left(B F=1 \mid X_{i}\right)=E\left(B F \mid X_{i}\right)
$$

Em que $B F$ é uma dummy que assume valor um se a mulher está em um domicílio que recebe o Programa Bolsa Família, tem um ou dois filhos e tem renda domiciliar per capita abaixo do ponto de corte para elegibilidade e zero caso tenha um ou dois filhos e tenha renda domiciliar per capita abaixo do ponto de corte para elegibilidade, mas não receba o programa; e $X_{i}$ é um vetor de características individuais de pré-tratamento. Rosebaum \& Rubin (1983) mostram que se a exposição ao tratamento é aleatória dentro de cada célula do vetor $X_{i}$, ela também é dada a variável unidimensional $P\left(X_{i}\right)$. O efeito de tratamento médio nos tratados (ATT) pode então ser calculado como:

$$
\begin{array}{r}
\tau \equiv E Y_{1 i}-Y_{0 i}\left|B F_{i}=1=E E Y_{1 i}-Y_{0 i}\right| B F_{i}=1, p\left(X_{i}\right) \\
=E E Y_{1 i}\left|B F_{i}=1, p\left(X_{i}\right)-E Y_{0 i}\right| B F_{i}=0, p\left(X_{i}\right) \mid B F_{i}=1
\end{array}
$$

Em que $Y_{1 i}$ e $Y_{0 i}$ são os resultados potenciais, respectivamente, nos tratados e nos não tratados, que assumem valor um se a mulher $i$ teve um filho nascido vivo nos últimos doze meses e zero caso contrário. Novamente, como exercício de robustez, vamos ampliar a amostra para até duas vezes o ponto de corte em renda e também para verificar os efeitos por faixa etária.

Além disso, faremos uma análise de sensibilidade para identificar a possibilidade de efeitos não observáveis estarem influenciando tanto a atribuição do tratamento quanto a variável de resultado (Rosenbaum 2002, Becker \& Caliendo 2007). Por último, usaremos o Método de Entropia para balancear melhor as covariáveis dos grupos de tratamento e controle e garantir a robustez dos resultados (Hainmueller 2012, Hainmueller \& Xu 2013).

Cada uma das estratégias usadas têm vantagens e desvantagens. A estratégia 1 tem a vantagem de construir um grupo de tratamento e um do controle e verificar o comportamento no tocante à fecundidade desses dois grupos antes e depois do programa. Entretanto, como não estamos usando nenhuma informação exatamente sobre se as famílias estão de fato recebendo o programa, não teremos certeza que o efeito encontrado será realmente o efeito do programa ou de outros fatores que aconteceram concomitantemente ao Bolsa Família que poderiam estar afetando cada grupo de forma diferente.

Na estratégia 2, usamos a informação de se a família recebe ou não o programa e interagimos essa informação com uma dummy que assume valor um se a mulher tem 2 filhos e zero caso tenha 3 filhos. A interpretação do coeficiente é feita da seguinte forma: dado que a família recebe o programa, qual a diferença na probabilidade da mulher ter tido um filho nos últimos doze meses entre as mulheres que tinham dois versus as que tinham três filhos. A vantagem dessa estratégia em relação à primeira é que estamos identificando se o domicílio recebe realmente o programa, mas, ao mesmo tempo, como estamos usando apenas um dado cross-section, não estamos incluindo os possíveis 
efeitos naqueles que não recebem o programa, nem estamos fazendo uma análise do comportamento do tratamento antes e depois, o que controlaria para efeitos fixos individuais.

Na estratégia 3, também usamos a informação de se o domicílio recebe o programa. Além disso, fazemos um "Propensity Score Matching", o que controla para seleção em observáveis. O coeficiente nos diz qual o efeito da pessoa receber o programa dado que ela é elegível. Ou seja, entre os que já deveriam receber o programa, será que existe efeito da pessoa efetivamente recebê-lo, visto que dessa forma, ela tem a certeza do recebimento de mais recursos ao ter mais um filho? A vantagem em relação à estratégia 2 é que controla para seleção em observáveis. A desvantagem em relação à estratégia 1 é que há o risco de variáveis omitidas estarem correlacionadas com o recebimento do programa e com a taxa de fecundidade.

Portanto, percebemos que as estratégias se complementam. A estratégia 1, minimiza preocupações com não observáveis, mas não nos fornece a certeza que o efeito é do programa, já que não há garantia que outras coisas não estejam afetando ao mesmo tempo os grupos escolhidos. A estratégia 3 usa informação do recebimento do programa, mas não resolve o problema das variáveis não observáveis. E a estratégia 2 resolve em parte o problema de não observáveis, mas não faz análise antes e depois. Ao mesmo tempo, usa a informação de recebimento do programa, mas não aproxima tratamento e controle por matching como acontece na estratégia 2.

\section{Resultados}

A Tabela 4 mostra os resultados da estratégia 1 . Na coluna 1 está a especificação básica e na coluna 2 está a mesma especificação com a ampliação da amostra para incluir as mulheres que recebem até duas vezes o ponto de corte para elegibilidade. As demais colunas repetem essa mesma lógica para cada uma das faixas etárias. Verifica-se que o coeficiente da interação tripla é não significativo na especificação básica. Isso significa que dado que a mulher está na faixa de elegibilidade, o fato dela ter dois filhos em comparação com ela ter três filhos não teve impacto significativo para a probabilidade de ela ter tido mais um filho nascido vivo nos últimos doze meses. Os resultados se mantêm quando ampliamos a amostra incluindo no tratamento as mulheres que ganham até duas vezes o ponto de corte em renda e também para todas as faixas etárias. A Tabela 5 repete a Tabela $4 \mathrm{com}$ a diferença que inclui no grupo de tratamento as mulheres com um e com nenhum filho. Os resultados dos coeficientes da interação tripla são, mais uma vez, não significativos. Isso quer dizer que, dado que a mulher é elegível em termos de renda, o fato dela ter dois filhos (e não três) e ainda poder receber benefício do programa ao ter mais um filho, não alterou a taxa de fecundidade dela posteriormente à implementação do programa.

A Tabela 6 mostra os resultados do modelo de diferenças em diferenças apenas com a dimensão tempo e a dimensão número de filhos condicional à renda domiciliar per capita. A primeira coluna usa na amostra apenas as mulheres que estão abaixo do ponto de corte. A segunda usa as mulheres que ganham acima do ponto de corte e abaixo de duas vezes o ponto de corte. A terceira, as que ganham acima de duas vezes o ponto de corte e abaixo de três vezes o ponto de corte. A quarta, as que ganham acima de três vezes o ponto 
Tabela 4: Regressão dif-em-dif-em-dif de fecundidade sobre tratamento em renda e número de filhos, por idade

\begin{tabular}{|c|c|c|c|c|c|c|c|c|}
\hline & \multicolumn{2}{|c|}{ Todos } & \multicolumn{2}{|c|}{ De 15 a 25 Anos } & \multicolumn{2}{|c|}{ De 26 a 35 Anos } & \multicolumn{2}{|c|}{ De 36 a 50 Anos } \\
\hline & Nasceu & Nasceu & Nasceu & Nasceu & Nasceu & Nasceu & Nasceu & Nasceu \\
\hline Dummy de 2 Filhos & $\begin{array}{l}0.001 \\
(0.003)\end{array}$ & $\begin{array}{r}-0.001 \\
(0.003)\end{array}$ & $\begin{array}{r}-0.006 \\
(0.011)\end{array}$ & $\begin{array}{r}-0.012 \\
(0.012)\end{array}$ & $\begin{array}{l}0.004 \\
(0.004)\end{array}$ & $\begin{array}{c}0.003 \\
(0.004)\end{array}$ & $\begin{array}{l}0.000 \\
(0.002)\end{array}$ & $\begin{array}{l}0.002 \\
(0.003)\end{array}$ \\
\hline Dummy de Renda & $\begin{array}{r}-0.001 \\
(0.003)\end{array}$ & $\begin{array}{c}-0.017^{* * * *} \\
(0.003)\end{array}$ & $\begin{array}{r}-0.001 \\
(0.014)\end{array}$ & $\begin{array}{c}-0.035^{* * * *} \\
(0.014)\end{array}$ & $\begin{array}{l}0.005 \\
(0.005)\end{array}$ & $\begin{array}{c}-0.013^{\text {****}} \\
(0.005)\end{array}$ & $\begin{array}{c}0.000 \\
(0.000)\end{array}$ & $\begin{array}{c}0.000 \\
(0.003)\end{array}$ \\
\hline Depois & $\begin{array}{r}-0.002 \\
(0.004)\end{array}$ & $\begin{array}{l}0.008 \\
(0.005)\end{array}$ & $\begin{array}{r}-0.029 \\
(0.023)\end{array}$ & $\begin{array}{c}0.042 \\
(0.028)\end{array}$ & $\begin{array}{c}0.002 \\
(0.006)\end{array}$ & $\begin{array}{l}0.007 \\
(0.007)\end{array}$ & $\begin{array}{c}0.004 \\
(0.003)\end{array}$ & $\begin{array}{l}0.011^{* *} \\
(0.005)\end{array}$ \\
\hline Renda ${ }^{\star} 2$ Filhos & $\begin{array}{l}0.011^{* * *} \\
(0.004)\end{array}$ & $\begin{array}{l}0.006^{*} \\
(0.003)\end{array}$ & $\begin{array}{l}0.026^{*} \\
(0.014)\end{array}$ & $\begin{array}{l}0.016 \\
(0.014)\end{array}$ & $\begin{array}{l}0.006 \\
(0.005)\end{array}$ & $\begin{array}{c}0.002 \\
(0.005)\end{array}$ & $\begin{array}{l}0.000 \\
(0.000)\end{array}$ & $\begin{array}{r}-0.002 \\
(0.003)\end{array}$ \\
\hline 2 Filhos ${ }^{\star}$ Depois & $\begin{array}{l}0.012^{* *} \\
(0.005)\end{array}$ & $\begin{array}{c}0.004 \\
(0.006)\end{array}$ & $\begin{array}{l}0.019 \\
(0.021)\end{array}$ & $\begin{array}{r}-0.027 \\
(0.028)\end{array}$ & $\begin{array}{r}0.010 \\
(0.006)\end{array}$ & $\begin{array}{r}0.010 \\
(0.008)\end{array}$ & $\begin{array}{c}0.001 \\
(0.003)\end{array}$ & $\begin{array}{r}-0.007 \\
(0.006)\end{array}$ \\
\hline Renda*Depois & $\begin{array}{r}-0.005 \\
(0.005)\end{array}$ & $\begin{array}{c}-0.017^{* * * *} \\
(0.006)\end{array}$ & $\begin{array}{l}0.007 \\
(0.024)\end{array}$ & $\begin{array}{c}-0.069^{* * *} \\
(0.028)\end{array}$ & $\begin{array}{c}-0.012^{*} \\
(0.007)\end{array}$ & $\begin{array}{c}-0.016^{* *} \\
(0.008)\end{array}$ & $\begin{array}{l}0.000 \\
(0.000)\end{array}$ & $\begin{array}{r}-0.009 \\
(0.006)\end{array}$ \\
\hline Renda $^{\star} 2$ Filhos ${ }^{\star}$ Depois & $\begin{array}{r}-0.006 \\
(0.006)\end{array}$ & $\begin{array}{l}0.005 \\
(0.007)\end{array}$ & $\begin{array}{r}-0.015 \\
(0.027)\end{array}$ & $\begin{array}{l}0.038 \\
(0.031)\end{array}$ & $\begin{array}{r}-0.001 \\
(0.009)\end{array}$ & $\begin{array}{l}0.000 \\
(0.009)\end{array}$ & $\begin{array}{l}0.000 \\
(0.000)\end{array}$ & $\begin{array}{l}0.008 \\
(0.007)\end{array}$ \\
\hline Controles & Sim & Sim & Sim & Sim & Sim & Sim & Sim & Sim \\
\hline Amostra & $\begin{array}{l}2 * \text { Ponto } \\
\text { de Corte }\end{array}$ & $\begin{array}{l}4^{*} \text { Ponto } \\
\text { de Corte }\end{array}$ & $\begin{array}{l}2 * \text { Ponto } \\
\text { de Corte }\end{array}$ & $\begin{array}{l}4^{*} \text { Ponto } \\
\text { de Corte }\end{array}$ & $\begin{array}{l}2 * \text { Ponto } \\
\text { de Corte }\end{array}$ & $\begin{array}{l}4^{*} \text { Ponto } \\
\text { de Corte }\end{array}$ & $\begin{array}{l}2 * \text { Ponto } \\
\text { de Corte }\end{array}$ & $\begin{array}{l}4^{*} \text { Ponto } \\
\text { de Corte }\end{array}$ \\
\hline Tratamento & $\begin{array}{c}\text { Ponto } \\
\text { de Corte }\end{array}$ & $\begin{array}{l}2 * \text { Ponto } \\
\text { de Corte }\end{array}$ & $\begin{array}{c}\text { Ponto } \\
\text { de Corte }\end{array}$ & $\begin{array}{l}2 * \text { Ponto } \\
\text { de Corte }\end{array}$ & $\begin{array}{c}\text { Ponto } \\
\text { de Corte }\end{array}$ & $\begin{array}{l}2 * \text { Ponto } \\
\text { de Corte }\end{array}$ & $\begin{array}{c}\text { Ponto } \\
\text { de Corte }\end{array}$ & $\begin{array}{l}2^{*} \text { Ponto } \\
\text { de Corte }\end{array}$ \\
\hline Observations & 122341,00 & 172773,00 & 18866,00 & 25128,00 & 61251,00 & 85949,00 & 42224,00 & 61696,00 \\
\hline R-squared & 0.06 & 0.06 & 0.05 & 0.06 & 0.02 & 0.02 & 0.01 & 0.01 \\
\hline
\end{tabular}

Regressão dif-em-dif-em-dif com variável dependente sendo se a mulher teve um filho nascido vivo nos últimos 12 meses e as

variáveis de interesse, se a renda domiciliar per capita era abaixo ou acima do ponto de corte que define elegibilidade ao programa, e uma dummy que assume 1 se a mulher tinha 2 filhos e 0 se tinha 3 filhos. A regressão inclui como controle dummies de região, região metropolitana, urbano-rural, idade, raça, anos de estudo, se havia aposentado ou pensionista no domicílio, se ela tinha cônjuge, se era chefe do domicílio, se o domicílio tinha água tratada, esgoto da rede geral, densidade de cômodos por pessoa e coleta de lixo. Foram usados dados das PNADs de 1995 a 2007.

${ }^{*}$ significante a $10 \%$; ${ }^{* *}$ significante a $5 \%$; ${ }^{* * *}$ significante a $1 \%$. 
Tabela 5: Regressão dif-em-dif-em-dif de fecundidade sobre tratamento em renda e número de filhos, por idade

\begin{tabular}{|c|c|c|c|c|c|c|c|c|}
\hline \multirow[b]{3}{*}{ Dummy de menos de 3 filhos } & \multirow{2}{*}{\multicolumn{2}{|c|}{ Todos }} & \multicolumn{2}{|c|}{ De 15 a 25 Anos } & \multicolumn{2}{|c|}{ De 26 a 35 Anos } & \multicolumn{2}{|c|}{ De 36 a 50 Anos } \\
\hline & & & Nasceu & Nasceu & Nasceu & Nasceu & Nasceu & Nasceu \\
\hline & $\begin{array}{l}0.016^{* * * *} \\
(0.003)\end{array}$ & $\begin{array}{l}0.004 \\
(0.003)\end{array}$ & $\begin{array}{c}0.001 \\
(0.010)\end{array}$ & $\begin{array}{c}-0.035^{* * * *} \\
(0.011)\end{array}$ & $\begin{array}{l}0.030^{* * * *} \\
(0.004)\end{array}$ & $\begin{array}{l}0.026^{* * * *} \\
(0.004)\end{array}$ & $\begin{array}{c}0.002 \\
(0.002)\end{array}$ & $\begin{array}{l}0.005^{* *} \\
(0.002)\end{array}$ \\
\hline Dummy de renda & $\begin{array}{l}0.004 \\
(0.003)\end{array}$ & $\begin{array}{c}-0.014^{* * *} \\
(0.003)\end{array}$ & $\begin{array}{c}0.002 \\
(0.013)\end{array}$ & $\begin{array}{c}-0.041^{* * * *} \\
(0.012)\end{array}$ & $\begin{array}{l}0.009^{*} \\
(0.005)\end{array}$ & $\begin{array}{r}-0.004 \\
(0.005)\end{array}$ & $\begin{array}{l}0.011^{* * * *} \\
(0.003)\end{array}$ & $\begin{array}{l}0.007^{* * *} \\
(0.002)\end{array}$ \\
\hline Depois & $\begin{array}{c}-0.008^{*} \\
(0.005)\end{array}$ & $\begin{array}{l}0.003 \\
(0.006)\end{array}$ & $\begin{array}{r}-0.031 \\
(0.020)\end{array}$ & $\begin{array}{l}0.027 \\
(0.026)\end{array}$ & $\begin{array}{l}0.000 \\
(0.006)\end{array}$ & $\begin{array}{l}0.005 \\
(0.008)\end{array}$ & $\begin{array}{r}-0.001 \\
(0.004)\end{array}$ & $\begin{array}{l}0.006 \\
(0.005)\end{array}$ \\
\hline Renda*Menos de 3 Filhos & $\begin{array}{l}0.015^{* * * *} \\
(0.004)\end{array}$ & $\begin{array}{l}0.018^{* * *} \\
(0.003)\end{array}$ & $\begin{array}{l}0.048^{* * *} \\
(0.014)\end{array}$ & $\begin{array}{l}0.061^{* * * *} \\
(0.012)\end{array}$ & $\begin{array}{l}0.006 \\
(0.006)\end{array}$ & $\begin{array}{r}-0.004 \\
(0.005)\end{array}$ & $\begin{array}{r}-0.005 \\
(0.003)\end{array}$ & $\begin{array}{c}-0.007^{* * * *} \\
(0.002)\end{array}$ \\
\hline Menos de 3 Filhos ${ }^{*}$ Depois & $\begin{array}{l}0.015^{* * * *} \\
(0.005)\end{array}$ & $\begin{array}{l}0.012^{* *} \\
(0.006)\end{array}$ & $\begin{array}{l}0.038^{*} \\
(0.020)\end{array}$ & $\begin{array}{c}0.012 \\
(0.026)\end{array}$ & $\begin{array}{l}0.010 \\
(0.007)\end{array}$ & $\begin{array}{l}0.009 \\
(0.009)\end{array}$ & $\begin{array}{l}0.004 \\
(0.004)\end{array}$ & $\begin{array}{r}-0.001 \\
(0.005)\end{array}$ \\
\hline Renda*Depois & $\begin{array}{r}-0.002 \\
(0.006)\end{array}$ & $\begin{array}{c}-0.014^{* * *} \\
(0.006)\end{array}$ & $\begin{array}{l}0.019 \\
(0.025)\end{array}$ & $\begin{array}{r}-0.045 \\
(0.028)\end{array}$ & $\begin{array}{r}-0.012 \\
(0.008)\end{array}$ & $\begin{array}{r}-0.014 \\
(0.009)\end{array}$ & $\begin{array}{l}0.002 \\
(0.005)\end{array}$ & $\begin{array}{r}-0.005 \\
(0.005)\end{array}$ \\
\hline Renda ${ }^{\star}$ Menos de 3 Filhos ${ }^{\star}$ Depois & $\begin{array}{r}-0.008 \\
(0.006)\end{array}$ & $\begin{array}{r}-0.001 \\
(0.007)\end{array}$ & $\begin{array}{r}-0.037 \\
(0.026)\end{array}$ & $\begin{array}{c}0.006 \\
(0.028)\end{array}$ & $\begin{array}{r}-0.004 \\
(0.009)\end{array}$ & $\begin{array}{l}0.001 \\
(0.010)\end{array}$ & $\begin{array}{l}0.005 \\
(0.005)\end{array}$ & $\begin{array}{l}0.002 \\
(0.005)\end{array}$ \\
\hline Controles & Sim & Sim & Sim & Sim & Sim & Sim & Sim & Sim \\
\hline Amostra & $\begin{array}{l}2 * \text { Ponto } \\
\text { de Corte }\end{array}$ & $\begin{array}{l}4^{*} \text { Ponto } \\
\text { de Corte }\end{array}$ & $\begin{array}{l}2^{*} \text { Ponto } \\
\text { de Corte }\end{array}$ & $\begin{array}{l}4^{\star} \text { Ponto } \\
\text { de Corte }\end{array}$ & $\begin{array}{l}2^{*} \text { Ponto } \\
\text { de Corte }\end{array}$ & $\begin{array}{l}4^{\star} \text { Ponto } \\
\text { de Corte }\end{array}$ & $\begin{array}{l}2 * \text { Ponto } \\
\text { de Corte }\end{array}$ & $\begin{array}{l}4^{\star} \text { Ponto } \\
\text { de Corte }\end{array}$ \\
\hline Tratamento & $\begin{array}{l}\text { Ponto } \\
\text { de Corte }\end{array}$ & $\begin{array}{l}2 * \text { Ponto } \\
\text { de Corte }\end{array}$ & $\begin{array}{l}\text { Ponto } \\
\text { de Corte }\end{array}$ & $\begin{array}{l}2 * \text { Ponto } \\
\text { de Corte }\end{array}$ & $\begin{array}{c}\text { Ponto } \\
\text { de Corte }\end{array}$ & $\begin{array}{l}2 \star \text { Ponto } \\
\text { de Corte }\end{array}$ & $\begin{array}{l}\text { Ponto } \\
\text { de Corte }\end{array}$ & $\begin{array}{l}2^{\star} \text { Ponto } \\
\text { de Corte }\end{array}$ \\
\hline Observações & 264080,00 & 452272,00 & 54733,00 & 91348,00 & 96839,00 & 157603,00 & 112508,00 & 203321,00 \\
\hline R-2 & 0.13 & 0.13 & 0.16 & 0.17 & 0.05 & 0.05 & 0.02 & 0.01 \\
\hline
\end{tabular}

Regressão dif-em-dif-em-dif com variável dependente sendo se a mulher teve um filho nascido vivo nos últimos 12 meses e as variáveis de interesse, se a renda domiciliar per capita era abaixo ou acima do ponto de corte que define elegibilidade ao programa, e uma dummy se a mulher tinha 3 filhos ou menos de 3 filhos. A regressão inclui como controle dummies de região, região metropolitana, urbano-rural, idade, raça, anos de estudo, se havia aposentado ou pensionista no domicílio, se ela tinha cônjuge, se era chefe do domicílio, se o domicílio tinha água tratada, esgoto da rede geral, densidade de cômodos por pessoa e coleta de lixo. Foram usados dados das PNADs de 1995 a 2007.

${ }^{*}$ significante a $10 \%$; ${ }^{* *}$ significante a $5 \%$; ${ }^{* *}$ significante a $1 \%$. 
de corte e abaixo de quatro vezes o ponto de corte. Verifica-se que apenas a segunda coluna tem o coeficiente da interação significativo. Isso poderia sugerir que, embora não tenha incentivado as mulheres na faixa de renda elegível e com dois filhos a terem mais filhos, o programa poderia estar incentivando aquelas que estão imediatamente acima desse ponto, já que tendo um filho a mais elas poderiam cair na faixa de renda elegível. Entretanto, como mais um exercício de robustez, a mesma tabela mostra na coluna (5) os resultados usando também a amostra da coluna (2), mas apenas até 2003 e fazendo um teste placebo, colocando a quebra estrutural em 1999. O coeficiente continua sendo significativo. Isso significa que, nesse grupo de faixa de renda o efeito está vindo de uma tendência pré-existente das mulheres com 3 filhos de reduzirem mais a fecundidade que as mulheres com 2 filhos. Portanto, nenhum efeito robusto do programa em fecundidade é encontrado pela estratégia 1.

Tabela 6: Regressão dif-em-dif de fecundidade sobre tratamento e número de filhos, por idade

\begin{tabular}{|c|c|c|c|c|}
\hline & $\begin{array}{c}(1) \\
\text { nasceu }\end{array}$ & $\begin{array}{c}(2) \\
\text { nasceu }\end{array}$ & $\begin{array}{c}(3) \\
\text { nasceu }\end{array}$ & $\begin{array}{c}(4) \\
\text { nasceu }\end{array}$ \\
\hline Dummy de 2 Filhos & $\begin{array}{l}0.015^{* * *} \\
(0.003)\end{array}$ & $\begin{array}{l}0.001 \\
(0.002)\end{array}$ & $\begin{array}{r}-0.004 \\
(0.003)\end{array}$ & $\begin{array}{l}0.001 \\
(0.004)\end{array}$ \\
\hline Depois & $\begin{array}{r}-0.002 \\
(0.004)\end{array}$ & $\begin{array}{c}-0.007^{*} \\
(0.004)\end{array}$ & $\begin{array}{r}-0.007 \\
(0.006)\end{array}$ & $\begin{array}{l}0.005 \\
(0.009)\end{array}$ \\
\hline Depois*dummy de 2 Filhos & $\begin{array}{l}0.008 \\
(0.005)\end{array}$ & $\begin{array}{l}0.011^{* * *} \\
(0.004)\end{array}$ & $\begin{array}{l}0.006 \\
(0.006)\end{array}$ & $\begin{array}{l}0.001 \\
(0.009)\end{array}$ \\
\hline Amostra & $\begin{array}{l}\text { Até } \\
\text { Corte }\end{array}$ & $\begin{array}{c}\text { Entre Corte } \\
\text { e } 2^{\star} \text { Corte }\end{array}$ & $\begin{array}{c}\text { Entre } 2^{*} \text { Corte } \\
\text { e } 3^{*} \text { Corte }\end{array}$ & $\begin{array}{c}\text { Entre } 3^{*} \text { Corte } \\
\text { e } 4^{\star} \text { Corte }\end{array}$ \\
\hline Observations & 54538,00 & 63690,00 & 33038,00 & 17394,00 \\
\hline R-squared & 0.06 & 0.05 & 0.07 & 0.07 \\
\hline
\end{tabular}

Regressão dif-em-dif com variável dependente sendo se a mulher teve um filho nascido vivo nos últimos 12 meses e as variáveis de interesse sendo uma dummy que assume valor um se a mulher tinha 2 filhos e zero se a mulher tinha 3 filhos e uma dummy depois do programa entrar em vigor. A regressão é condicional à renda domiciliar per capita. A coluna (1) inclui as mulheres que recebem até o ponto de corte em termos de renda domiciliar per capita, a coluna (2), entre o ponto de corte e duas vezes o ponto de corte, a coluna (3) entre duas vezes o ponto de corte três vezes o ponto de corte e a coluna (4) entre 3 vezes o ponto de corte e 4 vezes o ponto de corte. A coluna (5) repete o exercício da coluna (2), mas faz um teste placebo, mantendo na amostra apenas as observações anteriores a 2004 e colocando como se o programa tivesse começado em 2001. A regressão inclui como controle dummies de região, região metropolitana, urbano-rural, idade, raça, anos de estudo, se havia aposentado ou pensionista no domicílio, se ela tinha cônjuge, se era chefe do domicílio, se o domicílio tinha água tratada, esgoto da rede geral, densidade de cômodos por pessoa e coleta de lixo. Foram usados dados das PNADs de 1995 a 2007.

${ }^{*}$ significante a $10 \% ;{ }^{* *}$ significante a $5 \% ;{ }^{* * *}$ significante a $1 \%$.

A Tabela 7 mostra os resultados da estratégia 2, para a especificação básica, para a amostra ampliada até duas vezes o ponto de corte em renda e por faixa etária. Mais uma vez verifica-se que a maioria dos coeficientes da interação entre a dummy de recebimento do programa e a dummy de dois filhos é não significativa. A Tabela 8 amplia o tratamento também para mulheres com um filho e os resultados não se alteram. Isso significa que, dado que a família recebe o Bolsa Família, as mulheres com dois filhos não têm incentivo maior que as que têm três filhos para ter mais um filho. Ou seja, o modelo estima que dado que o domicílio recebe o programa, o nosso grupo de tratamento (as mulheres com dois filhos que ainda podem receber mais um benefício) não 
tem uma probabilidade maior de ter tido um filho nos últimos 12 meses que nosso grupo de controle (as mulheres com três filhos que não podem receber outro benefício). A Tabela A.1 do Apêndice Apêndice A mostra os principais resultados dessas duas primeiras estratégias estimados por probit. Vemos que os resultados não se modificam significativamente.

A Tabela 9 mostra as características dos que recebem e dos que não recebem o Programa Bolsa Família sem e com o matching. Verifica-se que após o matching as características ficam bem mais semelhantes. Entretanto, embora com o Propensity Score Matching, as características estejam balanceadas por bloco, as médias do grupo de tratamento e do grupo de controle ainda tem diferenças estatisticamente significativas. Vamos cuidar desse problema posteriormente rodando o Método de Entropia de balanceamento.

A Tabela 10 mostra os determinantes do recebimento do programa. Podese ver que a maioria dos coeficientes tem o sinal esperado. As mulheres com maior escolaridade têm uma menor probabilidade de pertencer a um domicílio que receba o programa. As mulheres urbanas, que moram em domicílios com Rede Geral de Esgoto, que têm apenas um filho (contra as que têm dois) e com maior renda domiciliar per capita também têm uma probabilidade menor de receber o programa.

A Tabela 11 mostra os resultados do efeito de tratamento médio nos tratados. As duas primeiras linhas mostram os efeitos para todas as faixas etárias, a primeira usando apenas as mulheres com renda domiciliar per capita abaixo do ponto de corte de elegibilidade para o programa e a segunda usando até duas vezes o ponto de corte na amostra. As demais linhas mostram a mesma coisa de acordo com a faixa etária. Verifica-se novamente que nenhum dos coeficientes é significativo, ou seja, nenhum efeito robusto do Bolsa Família em fecundidade é encontrado. Além disso, embora não significativos todos os coeficientes são negativos. Ou seja, se os resultados sugerem alguma coisa é que o impacto do Bolsa Família é negativo. Entretanto, como os coeficientes são não significativos, o mais correto é considerar que não há efeito do programa sobre fecundidade.

Embora o método do Propensity Score Matching resolva o problema da seleção em observáveis, ainda há a possibilidade de características não observáveis terem correlação com a atribuição de tratamento e ao mesmo tempo com a variável de resultado (probabilidade de ter tido um filho nos últimos 12 meses). Para tentar estimar o quanto isso pode ser um problema, faremos um teste de sensibilidade de Rosenbaum (Rosenbaum 2002, Becker \& Caliendo 2007). A Tabela 12 apresenta os resultados deste teste para o nosso caso.

Os resultados apresentados nessa tabela mostram que características não observadas podem causar uma diferença na probabilidade de uma mulher ser beneficiária do PBF em até $25 \%$ sem alterar os resultados do efeito de tratamento nos tratados por vizinho mais próximo. Entretanto, se essa diferença de probabilidade for de $30 \%$, é possível que o coeficiente esteja subestimado. Como o coeficiente é negativo, se ele for maior, ele ficará ainda mais próximo do zero, o que mitiga o problema da subestimação. Ainda assim, há a preocupação do viés ser grande o bastante de modo que o coeficiente passe a ser positivo e significativo.

Para diminuir essa preocupação, é importante reforçar que foram utilizadas outras metodologias nesse trabalho que levam em conta possíveis efeitos de não observáveis. Por exemplo, ao utilizarmos a metodologia de diferenças em diferenças usando dados de 1995 a 2007, não foram encontradas evidên- 
Tabela 7: Regressão de fecundidade sobre quem recebe Bolsa Família, por idade

\begin{tabular}{l|rr|rr|rr|rr}
\hline & \multicolumn{2}{|c|}{ Todos } & \multicolumn{2}{c|}{ De 15 a 25 Anos } & \multicolumn{2}{c}{ De 26 a 35 Anos } & \multicolumn{2}{c}{ De 36 a 50 Anos } \\
& Nasceu & Nasceu & Nasceu & Nasceu & Nasceu & Nasceu & Nasceu & Nasceu \\
\hline Dummy 1 ou 2 Filhos & $0.035^{* * *}$ & $0.019^{* * *}$ & $0.085^{* *}$ & 0.038 & $0.034^{* *}$ & $0.020^{* *}$ & 0.002 & -0.002 \\
& $(0.012)$ & $(0.007)$ & $(0.041)$ & $(0.029)$ & $(0.016)$ & $(0.009)$ & $(0.015)$ & $(0.008)$ \\
Recebe BF & 0.009 & 0.001 & 0.026 & 0.018 & 0.003 & -0.003 & 0.001 & 0.001 \\
& $(0.013)$ & $(0.008)$ & $(0.049)$ & $(0.038)$ & $(0.017)$ & $(0.011)$ & $(0.016)$ & $(0.010)$ \\
Recebe BF*2 Filhos & -0.013 & -0.004 & 0.059 & 0.047 & $-0.038^{*}$ & -0.020 & -0.001 & 0.003 \\
& $(0.016)$ & $(0.010)$ & $(0.058)$ & $(0.043)$ & $(0.021)$ & $(0.013)$ & $(0.019)$ & $(0.011)$ \\
Ccontroles & 5269,00 & 10758,00 & 842,00 & 1533,00 & 2696,00 & 5633,00 & 1731,00 & 3592,00 \\
Amostra & 0.05 & 0.04 & 0.05 & 0.04 & 0.02 & 0.02 & 0.02 & 0.01 \\
\hline Observations & 8456,00 & 19523,00 & 1703,00 & 3674,00 & 3655,00 & 8459,00 & 3098,00 & 7390,00 \\
R-squared & 0.07 & 0.06 & 0.04 & 0.04 & 0.03 & 0.03 & 0.02 & 0.01 \\
\hline
\end{tabular}

Regressão dif-em-dif com variável dependente sendo se a mulher teve um filho nascido vivo nos últimos 12 meses e as variáveis de interesse sendo se a mulher recebia Bolsa Família em 2006 e uma dummy que assume valor um se ela tem dois filhos e assume valor zero se ela tem três filhos. A regressão inclui como controle dummies de região, região metropolitana, urbano-rural, idade, raça, anos de estudo, se havia aposentado ou pensionista no domicílio, se ela tinha cônjuge, se era chefe do domićlio, se o domicílio tinha água tratada, esgoto da rede geral, densidade de cômodos por pessoa e coleta de lixo. Foram usados dados da PNAD 2006.

${ }^{*}$ significante a $10 \%$; ${ }^{* *}$ significante a $5 \%$; ${ }^{* * *}$ significante a $1 \%$. 
Tabela 8: Regressão de fecundidade sobre quem recebe Bolsa Família, por idade

\begin{tabular}{l|ccc|cc|cc|cc}
\hline & \multicolumn{2}{|c|}{ Todos } & \multicolumn{2}{c|}{ De 15 a 25 anos } & \multicolumn{2}{c|}{ De 26 a 35 anos } & \multicolumn{2}{c}{ De 36 a 50 anos } \\
& nasceu & nasceu & nasceu & nasceu & nasceu & nasceu & nasceu \\
nasceu
\end{tabular}

Regressão dif-em-dif com variável dependente sendo se a mulher teve um filho nascido vivo nos últimos 12 meses e as variáveis de

interesse sendo se a mulher recebia Bolsa Família em 2006 e uma dummy que assume valor um se ela tem um ou dois filhos e assume

valor zero se ela tem três filhos. A regressão inclui como controle dummies de região, região metropolitana, urbano-rural, idade, raça,

anos de estudo, se havia aposentado ou pensionista no domicílio, se ela tinha cônjuge, se era chefe do domicílio, se o domicílio tinha água

tratada, esgoto da rede geral, densidade de cômodos por pessoa e coleta de lixo. Foram usados dados da PNAD 2006.

${ }^{*}$ significante a $10 \%$; ${ }^{* *}$ significante a $5 \%$; ${ }^{* * *}$ significante a $1 \%$. 
Tabela 9: Estatísticas descritivas com e sem matching, PNAD 2006

\begin{tabular}{l|cc|ccc}
\hline & \multicolumn{2}{|c|}{ Sem matching } & \multicolumn{3}{c}{ Com matching } \\
& Não Recebe BF & Recebe BF & Não Recebe BF & Recebe BF & Dif de Médias \\
\hline Anos de Estudo & 6.875 & 5.900 & 6.613 & 6.325 & $0.288^{*}$ \\
Idade & 31.462 & 32.753 & 33.065 & 33.210 & -0.145 \\
Branca & 0.311 & 0.298 & 0.323 & 0.333 & -0.010 \\
Inativa ou Desempregada & 0.683 & 0.620 & 0.657 & 0.650 & 0.007 \\
Metrópole & 0.354 & 0.213 & 0.303 & 0.257 & $0.046^{* *}$ \\
Água & 0.836 & 0.818 & 0.818 & 0.824 & -0.006 \\
Esgoto & 0.368 & 0.270 & 0.348 & 0.311 & $0.037^{*}$ \\
Urbano & 0.770 & 0.643 & 0.814 & 0.771 & $0.042^{* *}$ \\
Lixo & 0.767 & 0.651 & 0.825 & 0.789 & $0.035^{*}$ \\
Densidade & 1.371 & 1.352 & 1.403 & 1.402 & 0.001 \\
Renda dom. per capita & 77.109 & 68.664 & 76.026 & 73.225 & $2.801^{*}$ \\
Tem um Filho & 0.463 & 0.339 & 0.374 & 0.327 & $0.047^{*}$ \\
Tem Cônjuge & 0.773 & 0.802 & 0.773 & 0.781 & -0.008 \\
Chefe & 0.265 & 0.225 & 0.270 & 0.253 & $0.017^{*}$ \\
Tem apos. ou pens. no dom. & 0.036 & 0.037 & 0.040 & 0.042 & -0.002 \\
Norte/Nordeste & 0.610 & 0.741 & 0.623 & 0.666 & $-0.043^{*}$ \\
\hline * significante a 10\%;** significante a 5\%*** significante a 1\%. & & &
\end{tabular}

${ }^{*}$ significante a $10 \% ;{ }^{* *}$ significante a $5 \%{ }^{* * * *}$ significante a $1 \%$. 
Tabela 10: Probabilidade de receber o Programa Bolsa Família

\begin{tabular}{|c|c|c|}
\hline & Recebe BF & Recebe BF \\
\hline Anos de Estudo & $\begin{array}{c}-0.033^{* * * *} \\
(0.005)\end{array}$ & $\begin{array}{c}-0.038^{* * * *} \\
(0.003)\end{array}$ \\
\hline Idade & $\begin{array}{l}0.006^{* * *} \\
(0.002)\end{array}$ & $\begin{array}{r}-0.002 \\
(0.001)\end{array}$ \\
\hline Branco & $\begin{array}{r}-0.022 \\
(0.035)\end{array}$ & $\begin{array}{l}0.046^{* *} \\
(0.023)\end{array}$ \\
\hline Inativa ou Desempregada & $\begin{array}{r}-0.051 \\
(0.037)\end{array}$ & $\begin{array}{c}-0.169^{* * *} \\
(0.023)\end{array}$ \\
\hline Água Tratada & $\begin{array}{l}0.210^{* * * *} \\
(0.054)\end{array}$ & $\begin{array}{l}0.086^{* *} \\
(0.036)\end{array}$ \\
\hline Esgoto da Rede Geral & $\begin{array}{c}-0.064^{*} \\
(0.039)\end{array}$ & $\begin{array}{c}-0.163^{* * *} \\
(0.024)\end{array}$ \\
\hline Urbano e Metropolitano & $\begin{array}{l}-0.288^{* * *} \\
(0.064)\end{array}$ & $\begin{array}{c}-0.139^{* * *} \\
(0.043)\end{array}$ \\
\hline Lixo Coletado & $\begin{array}{c}-0.123^{* *} \\
(0.063)\end{array}$ & $\begin{array}{c}-0.138^{* * *} \\
(0.044)\end{array}$ \\
\hline Densidade de Cômodos & $\begin{array}{c}-0.064^{*} \\
(0.033)\end{array}$ & $\begin{array}{c}-0.039^{*} \\
(0.022)\end{array}$ \\
\hline Renda Dom. per capita & $\begin{array}{c}-0.003^{* * *} \\
(0.000)\end{array}$ & $\begin{array}{c}-0.004^{* * *} \\
(0.000)\end{array}$ \\
\hline Tem um Filho & $\begin{array}{c}-0.318^{* * *} \\
(0.035)\end{array}$ & $\begin{array}{c}-0.297^{* * *} \\
(0.023)\end{array}$ \\
\hline Tem Cônjuge & $\begin{array}{r}-0.021 \\
(0.064)\end{array}$ & $\begin{array}{c}-0.135^{* * *} \\
(0.040)\end{array}$ \\
\hline Chefe & $\begin{array}{r}-0.063 \\
(0.059)\end{array}$ & $\begin{array}{c}-0.152^{* * *} \\
(0.038)\end{array}$ \\
\hline Tem apos. ou pens. no dom. & $\begin{array}{l}0.073 \\
(0.085)\end{array}$ & $\begin{array}{l}0.239^{* * * *} \\
(0.042)\end{array}$ \\
\hline Norte/Nordeste & $\begin{array}{l}0.423^{* * * *} \\
(0.055)\end{array}$ & $\begin{array}{l}0.397^{* * * *} \\
(0.023)\end{array}$ \\
\hline $\begin{array}{l}\text { Amostra } \\
\text { Observations }\end{array}$ & $\begin{array}{c}\text { Até Corte } \\
62170\end{array}$ & $\begin{array}{c}\text { Até } 2^{*} \text { Corte } \\
16242\end{array}$ \\
\hline
\end{tabular}

Regressão de escore de propensão em suporte comum com variável dependente sendo a probabilidade da mulher receber o programa e as variáveis explicativas sendo dummies de região, urbano e metropolitano, idade, raça, anos de estudo, se havia aposentado ou pensionista no domicílio, se ela tinha cônjuge, se era chefe do domicílio, se o domicílio tinha água tratada, esgoto da rede geral, densidade de cômodos por pessoa e coleta de lixo, dummy se a mulher tem um filho (versus ter dois filhos). Foram mantidos apenas as mulheres de um ou dois filhos com renda domiciliar per capita menor que o ponto de corte na coluna (1) e menor que duas vezes o ponto de corte na coluna (2). Foram usados dados da PNAD 2006.

* significante a $10 \%$; ${ }^{* *}$ significante a $5 \%$; significante a $1 \%$. 
Tabela 11: Efeito de tratamento nos tratados

\begin{tabular}{lccccc}
\hline & N. Treat. & N. Contr. & ATT & Std. Err. & \multicolumn{1}{c}{$t$} \\
\hline Amostra até Corte & 2690 & 1561 & -0.018 & 0.011 & -1.626 \\
Amostra até 2*Corte & 5188 & 3431 & -0.006 & 0.007 & -0.850 \\
De 15 a 25 Anos até Corte & 517 & 334 & -0.033 & 0.034 & -0.963 \\
De 15 a 25 anos até 2*Corte & 949 & 660 & 0.006 & 0.022 & 0.283 \\
De 26 a 35 Anos até Corte & 1240 & 615 & -0.028 & 0.019 & -1.474 \\
De 26 a 35 Anos até 2*Corte & 2294 & 1377 & -0.019 & 0.010 & -1.871 \\
\hline
\end{tabular}

Regressão de efeito de tratamento médio nos tratados feita em observações em suporte comum, com variável dependente sendo se a mulher teve um filho nascido vivo nos últimos 12 meses e o grupo de tratamento sendo as mulheres que recebem o Bolsa Família que têm um ou dois filhos e com renda domiciliar per capita até o ponto de corte ou duas vezes o ponto de corte e o controle sendo o mesmo grupo, com a diferença de não receber o programa. A regressão inclui como controle dummies de região, região metropolitana, urbano-rural, idade, raça, anos de estudo, se havia aposentado ou pensionista no domicílio, se ela tinha cônjuge, se era chefe do domicílio, se o domicílio tinha água tratada, esgoto da rede geral, densidade de cômodos por pessoa e coleta de lixo. Foram usados dados da PNAD 2006.

Tabela 12: Análise de sensibilidade de Rosenbaunm Bounds

\begin{tabular}{lrccc}
\hline \multicolumn{5}{c}{ Mantel-Haenszel (1959) Bounds para a Variável "Nasceu" } \\
\hline Gamma & Q_mh+ & Q_mh- & p_mh+ & p_mh- \\
1,00 & 4,81844 & 4,818440 & $7,20 \mathrm{E}-07$ & $7,20 \mathrm{E}-07$ \\
1,05 & 5,48656 & 4,152970 & $2,00 \mathrm{E}-08$ & 0,000016 \\
1,10 & 6,12547 & 3,519830 & $4,50 \mathrm{E}-10$ & 0,000216 \\
1,15 & 6,73819 & 2,916110 & $8,00 \mathrm{E}-12$ & 0,001772 \\
1,20 & 7,32705 & 2,339060 & $1,20 \mathrm{E}-13$ & 0,009666 \\
1,25 & 7,89410 & 1,786290 & $1,40 \mathrm{E}-15$ & 0,037026 \\
1,30 & 8,44112 & 1,255710 & 0,000000 & 0,104611 \\
1,35 & 8,96970 & 0,745484 & 0,000000 & 0,227990 \\
1,40 & 9,48123 & 0,254000 & 0,000000 & 0,399748 \\
1,45 & 9,97694 & 0,146084 & 0,000000 & 0,441927 \\
1,50 & 10,45800 & 0,604040 & 0,000000 & 0,272909 \\
1,55 & 10,92530 & 1,047100 & 0,000000 & 0,147527 \\
1,60 & 11,37980 & 1,476280 & 0,000000 & 0,069934 \\
\hline
\end{tabular}

Gamma: probabilidades de atribuição de tratamentoS diferentes devido a fatores não observados;

Q_mh+: Estatística de Mantel-Haenszel (Hipótese: Efeito de Tratamento está sobrestimado);

Q_mh-: Estatística de Mantel-Haenszel (Hipótese: Efeito de Tratamento está subestimado); p_mh+: Nível de significância (Hipótese: Efeito de Tratamento está sobrestimado); p_mh-: Nível de significância (Hipótese: Efeito de Tratamento está subestimado). 
cias de que as mulheres com dois filhos (que ainda podem ganhar mais um benefício, caso tenham um terceiro) aumentaram mais a probabilidade de ter mais um filho do que as mulheres com três filhos (que não se beneficiam tendo um filho a mais) após o programa ser estabelecido. Além disso, utilizando dados apenas de 2006, foi possível constatar que o fato da mulher ser beneficiária do $\mathrm{PBF}$, não aumenta a diferença de probabilidade entre as mulheres com dois e três filhos de terem um filho a mais. Se o programa tivesse efeito, esse aumento da diferença dessas probabilidades seria esperado, já que a mulher que recebe o programa tem a certeza que receberá um benefício a mais tendo um filho a mais, enquanto a que não recebe o programa, não teria tanto incentivo assim, pois não tem como saber se por conta disso irá passar a receber (já que ela já era elegível e mesmo assim não recebia).

Por último, apesar das evidências apresentadas de que o programa não teve efeito sobre fecundidade, mais um teste de robustez ainda será feito. Como mesmo depois do propensity score ser calculado as médias dos grupos de tratamento e controle ficaram ainda um pouco diferentes, será utilizado o Método de Entropia para balancear melhor as covariáveis nos dois grupos. Com isso, novos pesos serão atribuídos a cada mulher e o efeito de tratamento médio nos tratados será recalculado com esses novos pesos (Hainmueller 2012). A ideia é assim garantir a robustez dos resultados. Hainmueller \& Xu (2013) aplicaram a metodologia com os dados de LaLonde (1986) de um programa de treinamento e seu efeito nas variáveis de mercado de trabalho e mostraram que os resultados se aproximaram muito dos resultados experimentais.

A Tabela 13 mostra os resultados do balanceamento das covariáveis, depois de aplicada a metodologia. Percebe-se que as médias, variâncias e assimetrias das variáveis dos grupos de tratamento e controle com os novos pesos são exatamente iguais. Esse mesmo procedimento foi realizado para os diferentes cortes de amostras utilizados na Tabela 11.

Usando esses novos pesos, foram rodados novamente os mesmos coeficientes que tinham sido estimados e apresentados na Tabela 11. Esses coeficientes estão agora apresentados na Tabela 14. É possível verificar que em todos os casos o efeito do PBF sobre a fecundidade permanece não significativo. Com isso e com as demais metodologias utilizadas anteriormente, chega-se à conclusão que o programa de fato não aumentou o incentivo à fecundidade das beneficiárias.

É importante ressaltar, entretanto, que os dados utilizados são os dados disponíveis com informações do programa, que no caso da PNAD estão disponíveis apenas para 2004 e 2006. Nesse período, o dinheiro pago a cada família ainda era pouco e havia uma limitação em três benefícios variáveis. Essas podem ser algumas das razões pelas quais o efeito pode ser igual a zero. Posteriormente, o programa aumentou de três para cinco, o número de benefícios variáveis. Além disso, foram criados vários outros benefícios vinculados ao PBF, como o Benefício Variável Jovem, o Benefício Gestante, etc. O aumento do número de benefícios variáveis, em conjunto com o aumento do dinheiro recebido vinculado a outros benefícios podem ter alterado os incentivos relacionados à fecundidade e é possível que hoje o efeito seja diferente de zero. Portanto, novos artigos podem e devem se debruçar sobre dados mais recentes para tentar atualizar o calculo do efeito. 
Tabela 13: Balanceamento das variáveis pelo Método de Entropia

\begin{tabular}{|c|c|c|c|c|c|c|}
\hline & \multicolumn{6}{|c|}{ Antes do Balanceamento } \\
\hline & & Tratamento & & & Controle & \\
\hline & Média & Variância & Assimetria & Média & $\overline{\text { Variância }}$ & Assimetria \\
\hline Educação & 6.13400 & 11.78000 & 0.366700 & 7.25300 & 12.57000 & 0.05643 \\
\hline Idade & 34.03000 & 60.69000 & -0.009429 & 31.76000 & 66.67000 & 0.22120 \\
\hline Branco & 0.32920 & 0.22090 & 0.726900 & 0.33920 & 0.22420 & 0.67930 \\
\hline Desempregado & 0.63370 & 0.23220 & -0.554800 & 0.68470 & 0.21590 & -0.79520 \\
\hline Região Metropolitana & 0.26220 & 0.19350 & 1.081000 & 0.40060 & 0.24020 & 0.40560 \\
\hline Esgoto & 0.31780 & 0.21690 & 0.782700 & 0.41250 & 0.24240 & 0.35570 \\
\hline Água & 0.83460 & 0.13810 & -1.801000 & 0.83910 & 0.13510 & -1.84500 \\
\hline Urbano & 0.77940 & 0.17200 & -1.347000 & 0.86410 & 0.11740 & -2.12600 \\
\hline Lixo & 0.79560 & 0.16270 & -1.466000 & 0.87310 & 0.11080 & -2.24200 \\
\hline Densidade & 1.29800 & 0.22680 & 1.307000 & 1.34500 & 0.33150 & 3.38900 \\
\hline Renda Domiciliar per capita & 72.33000 & 1261.00000 & -0.583300 & 79.33000 & 1288.00000 & -0.92890 \\
\hline Tem um Filho & 0.4273 & 0.24480 & 0.293900 & 0.53100 & 0.24910 & -0.12430 \\
\hline Casal & 0.78890 & 0.16660 & -1.416000 & 0.78050 & 0.17140 & -1.35500 \\
\hline Chefe & 0.26160 & 0.19320 & 1.085000 & 0.27950 & 0.20140 & 0.98280 \\
\hline Domicílio tem Aposentado & 0.04222 & 0.04045 & 4.553000 & 0.03865 & 0.03717 & 4.78700 \\
\hline Sul/Sudeste & 0.27110 & 0.19770 & 1.030000 & 0.33800 & 0.22380 & 0.68470 \\
\hline \multirow[t]{4}{*}{ Norte/Nordeste } & 0.66700 & 0.22220 & -0.708600 & 0.53650 & 0.24870 & -0.14630 \\
\hline & \multicolumn{6}{|c|}{ Após o Balanceamento } \\
\hline & \multicolumn{3}{|c|}{ Tratamento } & \multicolumn{3}{|c|}{ Controle } \\
\hline & Média & Variância & Assimetria & Média & $\overline{\text { Variância }}$ & Assimetria \\
\hline Educação & 6.13400 & 11.78000 & 0.366700 & 6.13400 & 11.78000 & 0.36670 \\
\hline Idade & 34.03000 & 60.69000 & -0.009429 & 34.03000 & 60.69000 & -0.00934 \\
\hline Branco & 0.32920 & 0.22090 & 0.726900 & 0.32920 & 0.22090 & 0.72690 \\
\hline Desempregado & 0.63370 & 0.23220 & -0.554800 & 0.63360 & 0.23220 & -0.55470 \\
\hline Região Metropolitana & 0.26220 & 0.19350 & 1.081000 & 0.26220 & 0.19350 & 1.08100 \\
\hline Esgoto & 0.31780 & 0.21690 & 0.782700 & 0.31780 & 0.21690 & 0.78270 \\
\hline Água & 0.83460 & 0.13810 & -1.801000 & 0.834600 & 0.13810 & -1.80100 \\
\hline Urbano & 0.77940 & 0.17200 & -1.347000 & 0.77940 & 0.17200 & -1.34700 \\
\hline Lixo & 0.79560 & 0.16270 & -1.466000 & 0.79550 & 0.16270 & -1.46600 \\
\hline Densidade & 1.29800 & 0.22680 & 1.307000 & 1.29800 & 0.22700 & 1.31900 \\
\hline Renda Domiciliar per capita & 72.33000 & 1261.00000 & -0.583300 & 72.32000 & 1261.00000 & -0.58330 \\
\hline Tem um Filho & 0.42730 & 0.24480 & 0.293900 & 0.42730 & 0.24480 & 0.29390 \\
\hline Casal & 0.78890 & 0.16660 & -1.416000 & 0.78890 & 0.16660 & -1.41600 \\
\hline Chefe & 0.26160 & 0.19320 & 1.085000 & 0.26160 & 0.19320 & 1.08500 \\
\hline Domicílio tem Aposentado & 0.04222 & 0.04045 & 4.553000 & 0.04222 & 0.04045 & 4.55300 \\
\hline Sul/Sudeste & 0.27110 & 0.19770 & 1.030000 & 0.27110 & 0.19770 & 1.03000 \\
\hline Norte/Nordeste & 0.66700 & 0.22220 & -0.708600 & 0.66700 & 0.22220 & -0.70860 \\
\hline
\end{tabular}


Tabela 14: Efeito de tratamento nos tratados após entropia

\begin{tabular}{lccccc}
\hline & N Tratados & N Controles & ATT & Erro Padrão & Estatística $t$ \\
\hline Amostra até Corte & 4641 & 2143 & 0.009 & 0.010 & 0.831 \\
Amostra até 2*Corte & 7816 & 3033 & -0.001 & 0.008 & -0.140 \\
De 15 a 25 Anos até Corte & 897 & 519 & -0.271 & 0.170 & -1.592 \\
De 15 a 25 Anos até 2*Corte & 1430 & 795 & 0.021 & 0.046 & 0.446 \\
De 26 a 35 Anos até Corte & 1732 & 737 & -0.017 & 0.018 & -0.929 \\
De 26 a 35 Anos até 2*Corte & 2948 & 1072 & -0.017 & 0.015 & -1.180 \\
\hline
\end{tabular}

Regressão de efeito de tratamento médio nos tratados usando como pesos o

balanceamento por entropia, com variável dependente sendo se a mulher teve um filho nascido vivo nos últimos 12 meses e o grupo de tratamento sendo as mulheres que recebem o Bolsa Família que têm um ou dois filhos e com renda domiciliar per capita até o ponto de corte ou duas vezes o ponto de corte e o controle sendo o mesmo grupo, com a diferença de não receber o programa. A regressão inclui como controle dummies de região, região metropolitana, urbano-rural, idade, raça, anos de estudo, se havia aposentado ou pensionista no domicílio, se ela tinha cônjuge, se era chefe do domicílio, se o domicílio tinha água tratada, esgoto da rede geral, densidade de cômodos por pessoa e coleta de lixo. Foram usados dados da PNAD 2006.

\section{Conclusões}

Os programas condicionais de transferência de renda têm impacto significativo na redução da miséria, da pobreza e da desigualdade em vários países da América Latina (Das et al. 2005). Além disso, já foi mostrado em vários estudos, ausência de impactos em variáveis que os governos não gostariam que esses programas impactassem, como diminuição da oferta de trabalho (Parker \& Skoufias 2000) e presença de impacto em algumas variáveis que gostaríamos que realmente acontecesse, como aumento da frequência escolar, melhoria da saúde básica e nutrição das crianças e aumento do consumo das famílias (Rawlings \& Rubio 2005). A literatura demonstra também bastante preocupação com o possível impacto positivo desse tipo de programa sobre a fecundidade dos beneficiários (Janvry \& Sadoulet 2006, Skoufias 2001, Todd \& Wolpin 2006, Handa \& Davis 2006, Barrientos \& Dejong 2006). Este trabalho contribui para a literatura mostrando que esse impacto não é encontrado de forma robusta no caso do Bolsa Família, assim como também não é encontrada no PROGRESA e no RPS (Stecklov et al. 2006). Mais ainda, embora o montante dos recursos do PBF seja dependente do número de filhos (assim como é o PRAF em Honduras), não verificamos impacto significativo do PBF em fecundidade, que é o que acontece no PRAF. Uma das possíveis explicações é que as condicionalidades podem estar contribuindo para uma mudança do investimento na qualidade dos filhos em detrimento da quantidade de filhos, o que pode estar cancelando o efeito da diminuição dos custos de se ter filhos. Além disso, podem existir efeitos de planejamento familiar, devido à maior frequência das crianças na escola e à obrigação das mães de irem aos postos de saúde fazerem pré-natal, o que as coloca em contato com pessoal da área de saúde, que pode fazer aconselhamento no que diz respeito ao planejamento familiar e facilitar o acesso a métodos contraceptivos.

Entretanto, é importante frisar que não encontramos nenhum efeito robusto do Programa Bolsa Família na fecundidade dos beneficiários, usando dados que vão até 2007, quando o número de benefícios variáveis era no má- 
ximo três e quando outros benefícios vinculados ainda não tinham sido criados. É possível que a razão da ausência de impacto fosse exatamente por conta do pouco dinheiro recebido, que não chegava a estimular a fecundidade o suficiente para alguma diferença aparecer nos dados. Com o aumento do número de benefícios e, consequentemente, do valor total recebido, esses incentivos à fecundidade podem ter se alterado e mais pesquisa sobre o assunto torna-se necessária para investigar possíveis externalidades do programa em sua fase recente.

\section{Referências Bibliográficas}

Acs, G. (1996), 'The impact of welfare on young mothers' subsequent childbearing decisions', The Journal of Human Resources 31(4), 898-915.

Ai, C. \& Northon, E. C. (2003), 'Interaction terms in logit and probit models', Economic Letters 80, 123-129.

Barrientos, A. \& Dejong, J. (2006), 'Reducing child poverty with cash transfers: a sure thing?', Development Policy Review 24(5), 537-552.

Barros, R. P. (2007), A efetividade do salário mínimo em comparação à do Programa Bolsa Família como instrumento de redução da pobreza e da desigualdade, in R. P. Barros, M. N. Foguel \& G. Ulyssea, eds, 'Desigualdade de Renda no Brasil', Vol. 2, IPEA, Brasília.

Becker, G. S. (1960), An economic analysis of fertility, in A. Coale, ed., 'Demographic and Economic Change in Developed Countries', Princeton University Press, Princeton, NJ, pp. 209-231.

Becker, G. S. \& Lewis, H. G. (1973), 'On the interaction between the quantity and quality of children', Journal of Political Economy 82, S279-S288.

Becker, S. O. \& Caliendo, M. (2007), 'Sensitivity analysis for average treatment effects', The Stata Journal 7(1), 71-83.

Bongaarts, J. (1982), 'The fertility-inhibiting effects of the intermediate fertility variables', Studies in Family Planning 13(6/7), 179-189.

Boyer, G. R. (1989), 'Malthus was right after all - poor relief and birth-rates in Southeastern England', Journal of Political Economy 97(1), 93-114.

Cardoso, E. \& Souza, A. P. (2004), The impact of cash transfers on child labor and school attendance in Brazil. Working Paper n. 04-W07, Vanderbilt.

Chein, F., Andrade, M. V. \& Ribas, R. P. (2006), Políticas de transferência de renda e condição nutricional de crianças: uma avaliação do Bolsa Família. Belo Horizonte, Mimeo.

Cornelissen, T. \& Sonderhof, K. (2008), 'Inteff3: Stata module to compute marginal effects in a probit model with a triple $d u m m y$ variable interaction term'.

URL: http://ideas.repec.org/c/boc/bocode/s456903.html

Das, J., Do, Q. T. \& Özler, B. (2005), 'Reassessing conditional cash transfer programs', World Bank Research Observer 20(1), 57-80. 
Duarte, G. B. \& Silveira Neto, R. M. (2008), Avaliando o impacto do Programa Bolsa Família sobre a frequência escolar: o caso da agricultura familiar no Nordeste do Brasil, in 'Anais do XXXVI Encontro Nacional de Economia, ANPEC', Salvador.

Foguel, M. N. \& Barros, R. P. (2008), The effects of conditional cash transfer programs on adult labor supply: an empirical analysis using a time-seriescross-section sample of Brazilian municipalities, in 'Anais do XXXVI Encontro Nacional de Economia, ANPEC', Salvador.

Gathier, A. \& Hatzius, J. (1997), 'Family benefits and fertility: an econometric analysis', Population Studies 51(3), 295-306.

Hainmueller, J. (2012), 'Entropy balancing for causal effects: multivariate reweighting method to produce balanced samples in observational studies', Polit. Anal. 20, 25-46.

Hainmueller, J. \& Xu, Y. (2013), 'Ebalance: a Stata package for entropy balancing', Journal of Statistical Software 54(7).

Handa, S. \& Davis, B. (2006), 'The experience of conditional cash transfers in Latin America and Caribbean', Development Policy Review 24(5), 513-536.

Hoffmann, R. (2007), Transferências de renda e redução da desigualdade no Brasil e em cinco regiões, entre 1997 e 2005, in e. G. U. R. P. Barros, M. N. Foguel, ed., 'Desigualdade de Renda no Brasil: uma Análise da Queda Recente', Vol. 2, IPEA, Brasília.

Huzel, J. P. (1980), 'The demographic impact of the old poor law: more reflexions on Malthus', Econ. Hist. Rev. 22, 430-452.

Janvry, A. \& Sadoulet, E. (2006), 'Making conditional cash transfer programs more efficient: designing for maximum effect of the conditionality', The World Bank Economic Review 20(1), 1-29.

LaLonde, R. (1986), 'Evaluating the econometric evaluations of training programs with experimental data', American Economic Review 76(4), 604-620.

Medeiros, M. (2004), 'Os filhos dos pobres', Folha de São Paulo .

Norton, E. C., Wang, H. \& Ai, C. (2004), 'Computing interaction effects and standard errors in logit and probit models', The Stata Journal 4(2), 154-167.

Parker, S. W. \& Skoufias, E. (2000), The impact of PROGRESA on work, leisure, and time allocation, Final Report, International Food Policy Research Institute.

Rawlings, L. B. \& Rubio, G. M. (2005), 'Evaluating the impact of conditional cash transfer programs', World Bank Research Observer 20(1), 29-50.

Resende, A. C. C. \& Oliveira, A. M. H. C. (2006), 'Avaliando os resultados de um programa de transferência de renda: o impacto do Bolsa Escola sobre os gastos das famílias brasileiras', Estudos Econômicos 38(2), 235-265.

Rosenbaum, P. R. (2002), Observational Studies, 2 edn, New York, Springer. 
Rosenzweig, M. \& Schultz, T. P. (1985), 'The demand for and supply of births: fertility and its life cycle consequences', American Economic Review 75(5), 992-1015.

Schultz, T. (1997), The demand for children in low income countries, in M. R. Rosenzweig \& O. Stark, eds, 'Handbook of Population and Family Economics', Amsterdam, Elsevier Service.

Signorini, B. A. \& Queiroz, B. L. (2009), The impact of Bolsa Família Program in the beneficiary fertility. Mimeo.

Simões, P. \& Soares, R. B. (2012), The impact of Bolsa Família Program in the beneficiary fertility. (Mimeo).

Skoufias, E. (2001), PROGRESA and its impacts on the human capital and wefare of households in rural Mexico: a synthesis of the results of an evaluation by IFPRI, in 'International Food Policy Research Institute, Food Consumption and Nutrition Division', Washington, D.C.

Soares, F. V., Soares, S. S. D., Medeiros, M. \& Osório, R. G. (2007), Programas de transferência de renda no Brasil: impactos sobre a desigualdade, in e. G. U. R. P. de Barros, M. N. Foguel, ed., 'Desigualdade de Renda no Brasil: uma Análise da Queda Recente', Vol. 2, IPEA.

Stecklov, G., Winters, P., Todd, J. \& Regalia, F. (2006), Demographic externalities from poverty programs in developing countries: experimental evidence from Latin America. Working Paper Series n. 2006-1, American University, Washington, D.C.

Tavares, P. A. (2008), Efeito do Programa Bolsa Família sobre a oferta de trabalho das mães, in 'Anais do XXXVI Encontro Nacional de Economia, ANPEC', Salvador.

Todd, P. E. \& Wolpin, K. I. (2006), 'Assessing the impact of school subsidy program in Mexico: using a social experiment to validate a dynamic behavioral model of child schooling and fertility', American Economic Review 96(5), 1384-1417.

Whittington, L. A., Alm, J. \& Peters, H. E. (1990), 'Fertility and the personal exemption - implicit pronatalist policy in the United States', American Economic Review 80(3), 545-556.

Williams, R. G. (1987), Development of guidelines for child support orders, Final Report, U. S. Department of Health and Human Services, Office of Child Support Enforcement.

\section{Apêndice A}


Tabela A.1: Regressões probit de fecundidade, dif-em-dif-em-dif e cross section

\begin{tabular}{|c|c|c|c|c|c|}
\hline & \multicolumn{2}{|c|}{ Dif-dif-dif } & & \multicolumn{2}{|c|}{ Cross-section } \\
\hline & Nasceu & Nasceu & & Nasceu & Nasceu \\
\hline Dummy de 2 Filhos & $\begin{array}{l}0.005^{* * *} \\
(0.001)\end{array}$ & $\begin{array}{l}0.003^{* * *} \\
(0.001)\end{array}$ & Dummy 2 Filhos & $\begin{array}{l}0.212^{* *} \\
(0.086)\end{array}$ & $\begin{array}{l}0.146^{* *} \\
(0.064)\end{array}$ \\
\hline Dummy de Renda & $\begin{array}{l}0.003 \\
(0.002)\end{array}$ & $-{ }^{-0.013^{* * * *}}$ & Recebe BF & $\begin{array}{l}0.065 \\
(0.096)\end{array}$ & $\begin{array}{l}0.030 \\
(0.078)\end{array}$ \\
\hline Depois & $\begin{array}{c}0.002 \\
(0.001)\end{array}$ & $\begin{array}{l}0.002^{* *} \\
(0.001)\end{array}$ & Recebe $B F * 2$ Filhos & $\begin{array}{r}-0.001 \\
(0.001)\end{array}$ & $\begin{array}{r}-0.005 \\
(0.009)\end{array}$ \\
\hline Renda $^{\star} 2$ Filhos & $\begin{array}{c}0.003 \\
(0.002)\end{array}$ & $\begin{array}{c}0.004 \\
(0.003)\end{array}$ & & & \\
\hline 2 Filhos ${ }^{*}$ Depois & $\begin{array}{l}0.009^{* * * *} \\
(0.002)\end{array}$ & $\begin{array}{l}0.005^{* *} \\
(0.002)\end{array}$ & & & \\
\hline Renda*Depois & $\begin{array}{r}-0.003 \\
(0.003)\end{array}$ & $\begin{array}{c}-0.009^{* * *} \\
(0.003)\end{array}$ & & & \\
\hline Renda ${ }^{\star} 2$ Filhos ${ }^{\star}$ Depois & $\begin{array}{c}-0.006 \\
(0.005)\end{array}$ & $\begin{array}{c}0.005 \\
(0.007)\end{array}$ & & & \\
\hline Controles & Sim & Sim & & Sim & Sim \\
\hline Amostra & ${ }^{*}$ Ponto de Corte & $4^{\star}$ Ponto de Corte & & Até Corte & Até $2^{*}$ corte \\
\hline Tratamento & Ponto de Corte & $2^{*}$ Ponto de Corte & & & \\
\hline Observações & 122343 & 172775 & & 5269 & 10758 \\
\hline
\end{tabular}

Regressão probit de fecundidade. As duas primeiras colunas são um dif-em-dif-em-dif com variável dependente sendo se a mulher teve um filho nascido vivo nos últimos 12 meses e as variáveis de interesse se a renda domiciliar per capita era abaixo ou acima do ponto de corte que define elegibilidade ao programa e uma dummy que assume 1 se a mulher tinha 2 filhos e 0 se tinha 3 filhos. Nestas duas primeiras colunas todos os números reportados são os efeitos marginas do probit. As duas últimas são uma cross-section com a mesma variável dependente e na qual as variáveis de interesse são se a mulher recebia Bolsa Família em 2006 e uma dummy que assume valor um se ela tem dois filhos e assume valor zero se ela tem três filhos. Nestas duas últimas colunas apenas a variável de interação é reportada com efeito marginal. Para as demais variáveis, são reportados os coeficientes do probit. As regressões incluem como controle dummies de região, região metropolitana, urbano-rural, idade, raça, anos de estudo, se havia aposentado ou pensionista no domicílio, se ela tinha cônjuge, se era chefe do domicílio, se o domicílio tinha água tratada, esgoto da rede geral, densidade de cômodos por pessoa e coleta de lixo. Foram usados dados das PNADs de 1995 a 2007.

${ }^{*}$ significante a $10 \%{ }^{* *}$ significante a $5 \%$; ${ }^{* * *}$ significante a $1 \%$. 